\title{
Transcriptional Analysis of the Azospirillum brasilense Indole-3-Pyruvate Decarboxylase Gene and Identification of a cis-Acting Sequence Involved in Auxin Responsive Expression
}

\author{
A. Vande Broek, ${ }^{1}$ P. Gysegom, ${ }^{1}$ O. Ona, ${ }^{1}$ N. Hendrickx, ${ }^{1}$ E. Prinsen, ${ }^{2}$ J. Van Impe, ${ }^{3}$ and J. Vanderleyden ${ }^{1}$ \\ ${ }^{1}$ Centre of Microbial and Plant Genetics, K.U.Leuven, Heverlee, Belgium; ${ }^{2}$ Department of Plant Physiology and Biochemistry, \\ U.I.Antwerpen, Wilrijk, Belgium; ${ }^{3}$ Departement Chemische Ingenieurstechnieken, K.U.Leuven, Heverlee, Belgium
}

Submitted 14 June 2004. Accepted 17 November 2004.

\begin{abstract}
Expression of the Azospirillum brasilense ipdC gene, encoding an indole-3-pyruvate decarboxylase, a key enzyme in the production of indole-3-acetic acid (IAA) in this bacterium, is upregulated by IAA. Here, we demonstrate that the ipdC gene is the promoter proximal gene in a bicistronic operon. Database searches revealed that the second gene of this operon, named $i a a C$, is well conserved evolutionarily and that the encoded protein is homologous to the Escherichia coli protein SCRP-27A, the zebrafish protein ES1, and the human protein KNP-I/GT335 (HES1), all of unknown function and belonging to the DJ-1/PfpI superfamily. In addition to this operon structure, iaaC is also transcribed monocistronically. Mutation analysis of the latter gene indicated that the encoded protein is involved in controlling IAA biosynthesis but not ipdC expression. Besides being upregulated by IAA, expression of the ipdC-iaaC operon is $\mathrm{pH}$ dependent and maximal at acidic $\mathrm{pH}$. The ipdC promoter was studied using a combination of deletion analyses and site-directed mutagenesis. A dyadic sequence (ATTGTTTC(GAAT)GAAACAAT), centered at $\mathbf{- 4 8}$ was demonstrated to be responsible for the IAA inducibility. This bacterial auxin-responsive element does not control the pHdependent expression of ipdC-iaaC.
\end{abstract}

Additional keywords: azospirilla, auxin responsive element, IAA inducible.

Auxins constitute a class of phytohormones that are essential in diverse aspects of plant growth and development. The most prevalent naturally occurring auxin, indole-3-acetic acid (IAA), is known to regulate diverse aspects of plant growth and development, including cell division, cell extension, and cell differentiation and to play crucial roles in root initiation, apical dominance, tropisms, and senescence. Regulation of these processes is thought to involve auxin-induced changes in gene expression, and a number of plant genes that are up- or

A. Vande Broek and P. Gysegom made equal contributions to this article.

Corresponding author: J. Vanderleyden; Kasteelpark Arenberg 20, B-3001 Heverlee, Belgium; Telephone: +32 (0)16 321631; Fax: +32 (0)16 321966; E-mail: jozef.vanderleyden@agr.kuleuven.ac.be

Nucleotide sequence data reported are available in the DDBJ, EMBL, and the GenBank nucleotide sequence databases under the accession numbers U17699 (A. brasilense gltX) and AY608698 (iaaC). downregulated by auxin have been identified and further characterized (Hagen and Guilfoyle 2002). Within the promoters of these genes, cis elements with the consensus sequence TGTCNC that confer auxin responsiveness (referred to as auxin-response element or AuxRe) have been defined (Ulmasov et al. 1995).

In addition to production in plant tissues, IAA biosynthesis is also widespread among plant-associated bacteria and provides these bacteria with a mechanism to influence plant growth (Costacurta and Vanderleyden 1995; Patten and Glick 1996). In phytopathogenic bacteria such as Agrobacterium tumefaciens and pathovars of Pseudomonas syringae, IAA production has been implicated in the induction of plant tumors or plant galls (Comai and Kosuge 1982; Thomashow et al. 1984). In plant growth-promoting rhizobacteria such as Pseudomonas putida and bacteria of the genus Azospirillum, bacterial excretion of IAA was found to be responsible for the promotion of root growth (Kapulnik et al. 1985; Dobbelaere et al. 1999; Patten and Glick 2002b).

Biosynthesis of IAA in plants and bacteria proceeds through distinct biosynthetic routes and both tryptophan (Trp)-dependent and -independent pathways have been described (Eckardt 2001; Ljung et al. 2002). Bacteria primarily use Trp as a precursor for IAA biosynthesis, and IAA accumulates in high quantities when these bacterial cultures are supplemented with Trp. By means of feeding experiments with radioactive IAA precursors, we previously demonstrated the existence of multiple pathways for IAA biosynthesis in the plant growth stimulating rhizobacterium Azospirilum brasilense (Prinsen et al. 1993). A Trp-dependent pathway in A. brasilense was identified as the indole-3-pyruvic acid (IPyA) pathway (L-Trp $\rightarrow$ IPyA $\rightarrow$ indole-3-acetaldehyde $\rightarrow$ IAA) by cloning of the $A$. brasilense ipdC gene, encoding an IPyA decarboxylase (IPDC) (Costacurta et al. 1994), and by purifying two amino acid aminotransferases that catalyze the first step in this pathway (Soto-Urzua et al. 1996). IPDC is a key enzyme for IAA biosynthesis in this bacterium, as an ipdC knockout mutant was found to produce only $10 \%$ of the wild-type IAA production level, both in the absence and presence of Trp (Prinsen et al. 1993). In addition to $A$. brasilense, genes encoding IPDC have been cloned from IAA-producing bacterial species such as Enterobacter cloacae (Koga et al. 1991), Pseudomonas putida (Patten and Glick 2002b), Erwinia herbicola (Brandl and Lindow 1996), and Azospirillum lipoferum (Yagi et al. 2001) and from the cyanobacterium Nostoc (Sergeeva et al. 2002). In addition, the crystal structure of the Enterobacter cloacae IPDC protein was recently 
elucidated (Schütz et al. 2003). Although IPyA has been detected as an intermediate in IAA biosynthesis in plants (Tam and Normanly 1998), no plant gene encoding an enzymatic activity catalyzing the synthesis or conversion of IPyA has yet been identified.

Transcription analysis of the A. brasilense ipdC gene revealed that expression of the gene is not affected by exogeneous Trp but, in contrast, is activated by the end product of the pathway, IAA (Vande Broek et al. 1999). Up to now, the A. brasilense ipdC gene constitutes the only bacterial gene that has been described to be IAA inducible. The positive feedback regulation by IAA is responsible for the increasing ipdC expression levels during growth of an $A$. brasilense culture, with the highest expression levels in the stationary-growth phase. Similarly, as has been observed for auxin-inducible genes in higher plants, synthetic auxins such as 1-naphtaleneacetic acid and chlorophenoxy acids were found to upregulate ipdC expression (Vande Broek et al. 1999). Recently, IAA-responsive genes were also identified in Saccharomyces cerevisiae, and perception of IAA was found to cause differentiation of the yeast cells into a filamentous invasive form (Prusty et al. 2004). These findings suggest that proteins involved in IAA perception and signal transduction are not only present in higher plants but also in bacteria and fungi.

In this study, we aimed to identify regulatory elements involved in the IAA-inducible expression of the A. brasilense $i p d C$ gene. We undertook a detailed molecular analysis of the $5^{\prime}$ end of the ipdC gene and identified a promoter DNA element that is essential for transcriptional induction of the gene by auxin. Additionally, we found that expression of ipdC is controlled by the environmental $\mathrm{pH}$ as well as by IAA. Downstream of ipdC, we identified an open reading frame (ORF) that is cotranscribed with ipdC and encodes a putative repressor of IAA production.

\section{RESULTS}

\section{Genomic organization of the ipdC gene region.}

DNA sequence analysis of the regions adjacent to the $A$. brasilense ipdC gene revealed the presence of two additional complete ORFs, as illustrated in Figure 1. The ORFs were identified and the start codon was assigned on the basis of the GC content and the preferential codon usage. A first ORF (ORF1) was found upstream of the ipdC gene on the complementary strand and encodes a putative protein of 451 amino acids with a calculated molecular mass of 50,076 Da and a pI of 6.13. This ORF starts 402 bp upstream of ipdC and is preceded by a putative ribosome binding site ( -5 to -11 bases $5^{\prime}$ to the predicted start codon). The putative protein was found in database searches using the BLASTP and BLASTX programs to be very similar to glutamyl-tRNA synthetases. For example, the deduced protein sequence displays 49,49 , and $45 \%$ of amino acid identity with glutamyl-tRNA synthetase from Brucella melitensis, Mesorhizobium loti, and Rickettsia conorii, respectively, and was therefore designated as gltX (Fig. 1). A second ORF, named iaaC (discussed below), which is unidirectional with ipdC, is found immediately (99 bp) downstream of $i p d C$. It encodes a putative protein of 222 amino acids with an estimated molecular mass of 22,667 Da and a pI of 4.99. Database searches using the BLASTP and BLASTX programs revealed homology of the predicted amino acid sequence with bacterial proteins including the $E$. coli SCRP-27A protein (GenBank accession number AAC76241, $56 \%$ identity), a hypothetical protein from Pseudomonas aeruginosa (AAG08630, 58\% identity), a hypothetical protein from Salmonella enterica subsp. enterica serovar Typhi (CAD07844, $57 \%$ identity), the Yersinia pestis Elb2 protein (CAC92782, $53 \%$ identity), as well as with the human protein HES1 (or KPNI- $\alpha$ ) (BAA95554, 51\% identity) and the zebrafish protein ES1 (AAC76241, 34\% identity). The function of these proteins, however, is not yet known. Figure 2 shows the alignment of the deduced amino acid sequence of iaaC with the bacterial homologs, human HES1 and ES1 of zebrafish. Although conserved amino acids are distributed throughout the entire proteins, several clusters can be observed, suggesting potential functional importance of the conserved amino acids. Strikingly, the human protein HES1 and the zebrafish protein ES1 have additional N-terminal sequences as compared with the bacterial counterparts.

A search in the Pfam 7.3 database for specific protein domains revealed that all these homologs belong to the DJ-1/PfpI family (InterPro database accession number IPR002818 [EMBL-EBI], Pfam database accession number PF01965). This family includes many proteins of variable functions including proteins involved in thiamine biosynthesis (Mizote et al. 1996), RNA-binding proteins (Hod et al. 1999), proteins involved in protease activity (Halio et al. 1996), transcriptional regulators (Capela et al. 2001), and chaperones (Wilson et al. 2004), as well as many hypothetical proteins. The functional role of the DJ-1/PfpI family, however, is still unclear.

\section{Transcriptional organization of the ipdC gene region.}

As $i a a C$ is located immediately downstream of $i p d C$ and as both genes are in the same orientation, we examined a possible transcriptional linkage between ipdC and iaaC by Northern blot analyses. For this, an antisense RNA probe, which encompassed 538 bp of iaaC, was used. Total RNA was isolated from cells, grown to the late exponential phase, of the $A$. brasilense wild-type strains Sp245, the ipdC mutant FAJ0009, and the iaaC mutant FAJ0010. The construction of this iaaC mutant

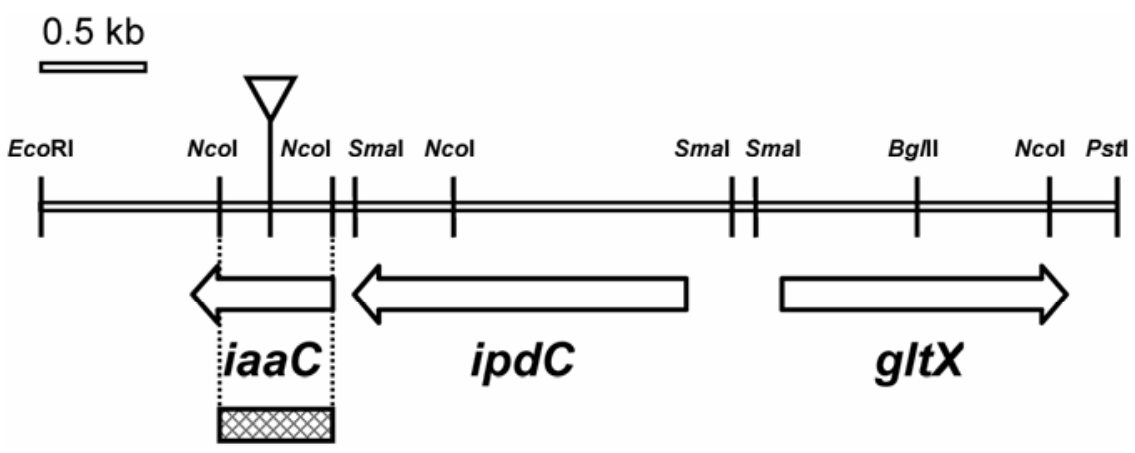

Fig. 1. Physical and genetic map of the ipdC region on the chromosome of Azospirillum brasilense Sp245. Horizontal arrows indicate direction of transcription. The position of Tn5 in the FAJ0010 mutant is indicated by a triangle. The internal NcoI fragment of iaaC, used as probe in the Northern blot experiment, is shown by a hatched box. 
by site-directed Tn 5 mutagenesis is explained below. Figure 3 shows the presence of two mRNA species, i.e., a 2.6- and a $0.7-\mathrm{kb}$ transcript hybridizing with the iaaC probe in RNA isolated from wild-type cells (lane 1). The 2.6-kb transcript corresponds to the predicted size of a bicistronic mRNA product encompassing the ipdC gene $(1.635 \mathrm{~kb})$ and iaaC $(0.669 \mathrm{~kb})$, while the $0.7-\mathrm{kb}$ transcript putatively corresponds to the monocistronic iaaC transcript. The detection of the $2.6-\mathrm{kb}$ transcript confirms our previous Northern blot results using an ipdC probe, in which a unique mRNA species of $2.6 \mathrm{~kb}$ was detected (Vande Broek et al. 1999). Both iaaC transcripts were absent in the iaaC mutant FAJ0010, proving the specificity of the $i a a C$ probe (Fig. 3, lane 2). Accordingly, only the monocistronic iaaC transcript was detected in total RNA isolated from the ipdC mutant FAJ0009 (Fig. 3, lane 3). No potential bacterial promoter sequence or transcriptional regulatory element could be identified in the intergenic region between ipdC and $i a a C$. Inspection of the region downstream of iaaC revealed the presence of a putative mRNA stem-loop structure that might function as a transcription terminator (nucleotides 22 to 65 , relative to the iaaC stop codon; $\Delta \mathrm{G}=-15.1 \mathrm{~kJ} / \mathrm{mol}$ ).

In order to evaluate the effect of IAA on iaaC transcription, additional Northern analyses with the $i a A C$ probe were performed on total RNA extracted from exponentially grown cells of Sp245, either IAA-induced or uninduced (Fig. 3, lanes 4 and 5). In agreement with the previously observed upregulation of ipdC expression by IAA (Vande Broek et al. 1999), the amount of ipdC-iaaC mRNA was found to be clearly higher in cells grown in the presence of exogeneously added IAA, as compared with uninduced cells. The amount of monocistronic iaaC mRNA, however, was independent of auxin addition.

pH modulates transcription of the ipdC-iaaC operon.

The observation that the Erwinia herbicola ipdC gene is transcriptionally induced by osmotic stress (Brandl and Lindow 1997) prompted us to investigate whether the expression of the A. brasilense ipdC gene is induced by environmental stress in addition to IAA. For this, $\beta$-glucuronidase (GUS) activity from strain Sp245, containing the translational ipdC-gusA fusion pFAJ64, was measured when grown under different physiological conditions. These conditions include growth at elevated temperatures, at various $\mathrm{pH}$ levels, in micro- and anaerobiosis, and under osmotic stress. For these analyses, Sp245(pFAJ64) cultures were grown in LB* (Luria-Bertani broth supplemented with $2.5 \mathrm{mM} \mathrm{CaCl}_{2}$ and $2.5 \mathrm{mM} \mathrm{MgSO}_{4}$ ) to an optical density at $600 \mathrm{~nm}$ of 0.4 and 0.9 (starter cultures), then were switched to the appropriate physiological conditions as detailed below, and after $5 \mathrm{~h}$ of additional growth, were assayed for GusA activity.

In contrast to the Erwinia herbicola ipdC gene, no upregulation of $A$. brasilense ipdC expression was observed when the osmotic strength of the culture medium was increased. In contrast, high concentrations of $\mathrm{NaCl}(4 \%)$ and polyethyleneglycol (PEG4000) (15\%) were even found to reduce ipdC expression (eight- and fivefold, respectively, as compared with growth in $\left.\mathrm{LB}^{*}\right)$. Growth at elevated temperatures $\left(37^{\circ} \mathrm{C}, 40^{\circ} \mathrm{C}\right)$ did not significantly affect ipdC expression, and also, no detectable differences in ipdC expression levels were observed
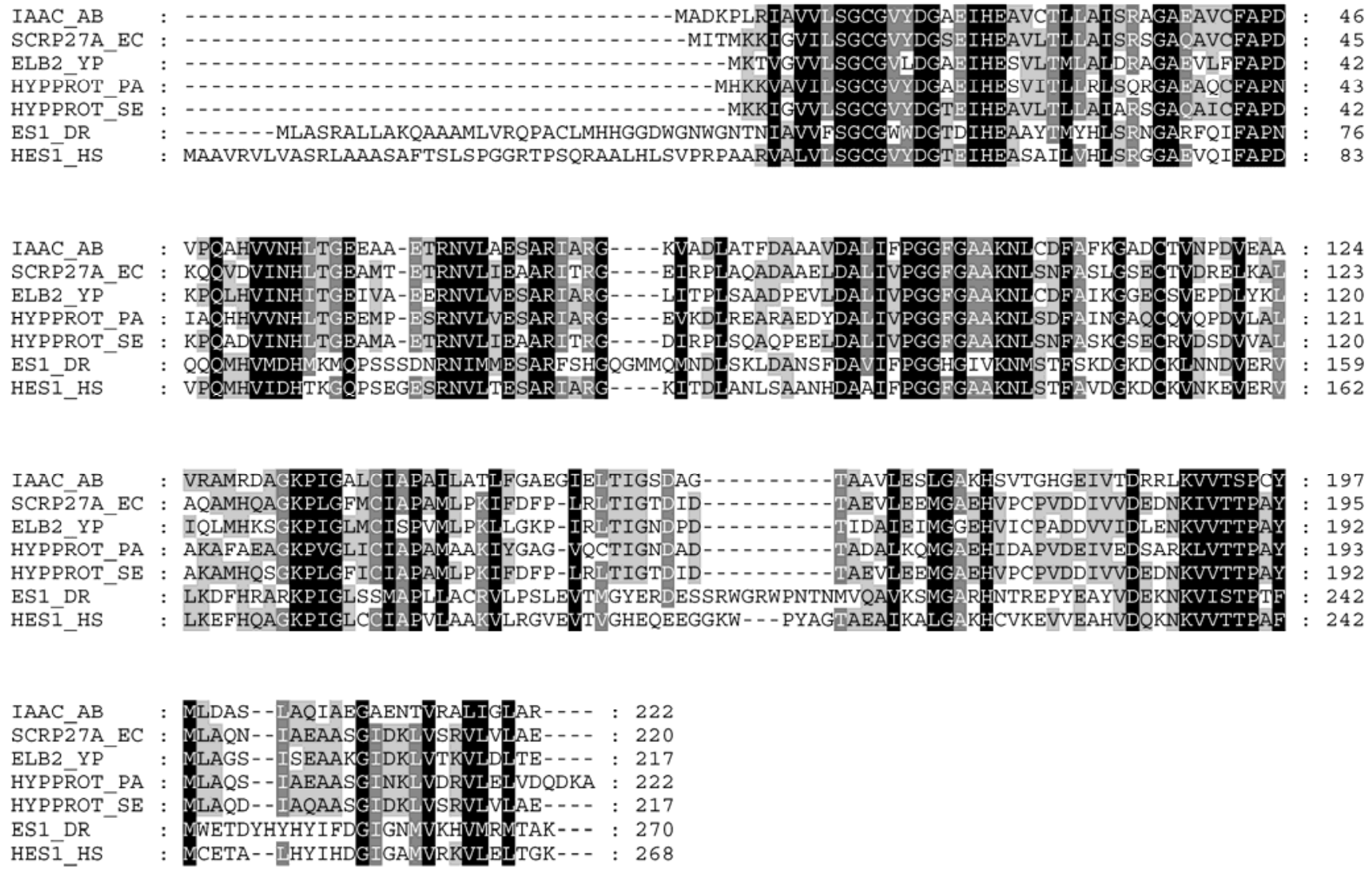

Fig. 2. Multiple-sequence alignment of the Azospirillum brasilense protein encoded by iaaC (IAAC_AB) with the Escherichia coli SCRP-27A protein (SCRP27A_EC, GenBank accession AAC76241), the human ES1 protein (HES1_HS, GenBank accession BAA95554), the zebrafish ES1 protein (ES1_DR, GenBank accession AAC60261), the Yersinia pestis Elb2 protein (ELB2_YP, GenBank accession CAC92782), and an unknown protein from Pseudomonas aeruginosa (HYPPROT_PA, GenBank accession AAG08630) and Salmonella enterica subsp. enterica serovar Typhi (HYPPROT_SE, GenBank accession CAD07844). The alignments were generated by ClustalW. Shadings were obtained using the Genedoc program. Black shading indicates $100 \%$ identical or conserved (D/N, E/Q, S/T, K/R, F/Y/W, L/I/V/M) residues; dark gray shading indicates 80 to $99 \%$ identical or conserved residues, and light gray shading indicates 60 to $79 \%$ identical or conserved residues. Gaps were introduced to maximize the similarity. Numbers on the right indicate amino acid positions. 
when cells were grown at oxygen tensions between 1 and $21 \%$. However, lowering the oxygen pressure below $1 \%$ progressively reduced the ipdC induction level (threefold reduction at an oxygen tension of $0.8 \% \mathrm{O}_{2}, 15$-fold reduction at an oxygen tension of $0.4 \%$ as compared with aerobically grown cells). The most pronounced effect on ipdC expression, however, was caused by the external $\mathrm{pH}$. As shown in Figure 4, shifting the $\mathrm{pH}$ to an acidic level strongly enhances ipdC expression, while a gradual decrease in the expression level is observed when the $\mathrm{pH}$ is raised. Maximum induction of ipdC was observed at $\mathrm{pH} 5.5$, which is equivalent to a threefold

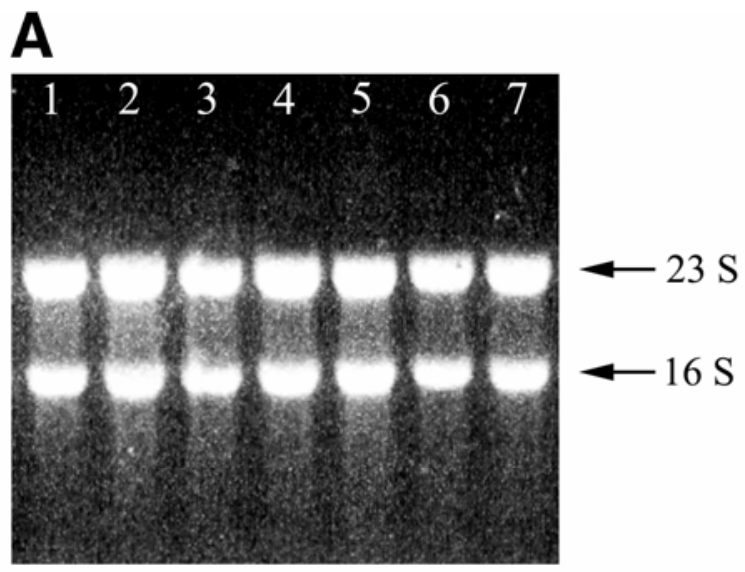

B

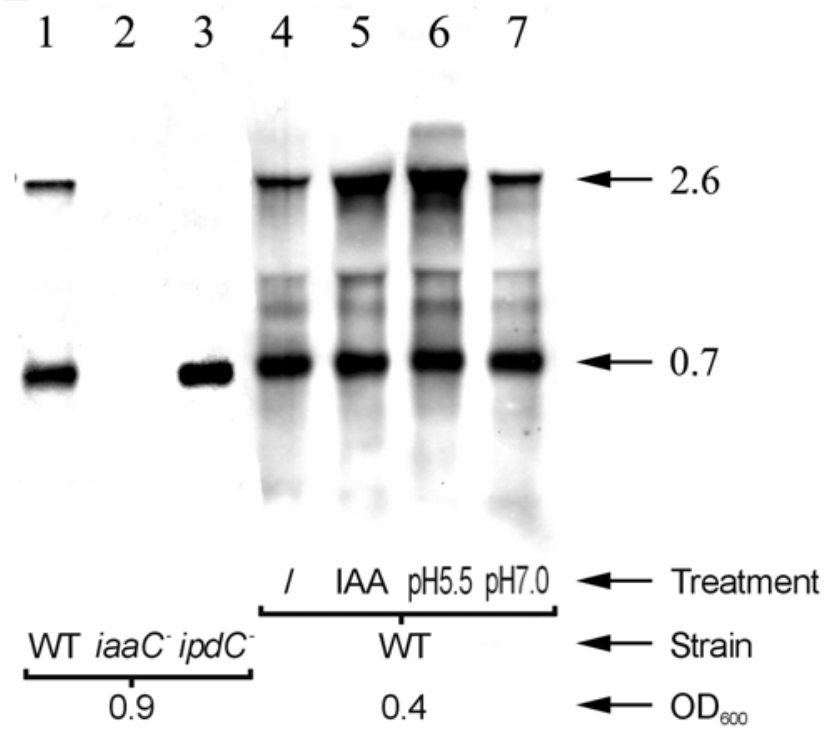

Fig. 3. Northern blot analysis of RNA extracted from cells of Azospirillum brasilense wild-type, ipdC mutant and iaaC mutant strains. A, Blot of total RNA (10 $\mu \mathrm{g}$ per lane) isolated from A. brasilense iaaC mutant (lane 2), ipdC mutant (lane 3), and wild-type (lanes 1 and 4 to 7) strains. RNA was visualized by epi-illumination with UV light. Cells were harvested at an optical density at $600 \mathrm{~nm}\left(\mathrm{OD}_{600}\right)$ of 0.9 (lanes 1 to 3 ) or 0.4 (lanes 4 to 7 ). To measure the effect of indole-3-acetic acid (IAA) on the transcription of iaaC, a wild-type culture at $\mathrm{OD}_{600}=0.4$ was divided in two and was further incubated for $3 \mathrm{~h}$ at $30^{\circ} \mathrm{C}$ in the absence (lane 4) or presence (lane 5) of exogenously added IAA at $1 \mathrm{mM}$. To evaluate the effect of $\mathrm{pH}$, a wild-type culture at $\mathrm{OD}_{600}=0.4$ was divided into two parts and was further incubated for $5 \mathrm{~h}$ at $\mathrm{pH} 5.5$ (lane 6) and 7.0 (lane 7) after buffering the growth medium with distinct buffers. The positions of the $16 \mathrm{~S}$ and $23 \mathrm{~S}$ ribosomal RNAs are indicated at the right. B, RNA blot analysis of the same samples as in section A after hybridization with a digoxygeninlabeled iaaC-derived riboprobe. The sizes of the iaaC transcripts (in kilobases) are indicated at the right and were determined relative to RNA standards that were electrophoresed in the same gel. increase in transcriptional activity of ipdC as compared with that at $\mathrm{pH} 7$ and to a 16-fold increase as compared with that at $\mathrm{pH}$ 8.5. We could not test cells exposed to $\mathrm{pH}$ values below 5.5 or above 8.5 , as cells started flocculating under these conditions.

To confirm the observed induction of the ipdC-gusA fusion in cells growing at an acidic $\mathrm{pH}$, total RNA isolated from Sp245 grown for $5 \mathrm{~h}$ in LB* buffered at $\mathrm{pH} 5.5$ and 7 was analyzed by quantitative Northern analysis, using the probe specific for iaaC (Fig. 3, lanes 6 and 7). Clearly, the 2.6-kb ipdCiaaC transcript was present in much higher amounts when cells were incubated under acidic conditions (Fig. 3) than when they were grown in neutral medium (Fig. 3) or in an alkaline medium (data not shown). However, as has been observed for the upregulation by IAA, the amount of the monocistronic $i a a C$ transcript was found to be independent of the culture $\mathrm{pH}$ level.

pH affects IAA production capacity of A. brasilense $\mathrm{Sp} 245$.

To determine whether the acid-mediated ipdC induction also reflects a higher IAA production capacity of $A$. brasilense at acidic $\mathrm{pH}$ levels, the kinetics of IAA production of $\mathrm{Sp} 245$ were determined when cultured in a chemostat at a constant $\mathrm{pH}$ of 6.3 or 6.8. As can be concluded from Figure 5, the culture $\mathrm{pH}$ level has a strong effect on the IAA biosynthetic capacity. Growth of Sp245 at pH 6.3 resulted in an approximately 40fold enhanced IAA production capacity in the stationary growth phase, as compared with that at $\mathrm{pH} 6.8$.

\section{Mapping of the ipdC transcription initiation site and identification of putative cis-controlling elements in the $5^{\prime}$ flanking region.}

To determine the start site of transcription of the A. brasilense ipd $C$ gene, primer extension experiments were performed. To facilitate detection of ipdC mRNA, we used strain Sp245(pFAJ64) containing the ipdC-gusA fusion. Using a primer specific for the ipdC structural gene (DP-ipdc03AS) or a primer specific for the gusA structural gene (OWB609) on RNA samples isolated from stationary grown cultures, a single transcription initiation

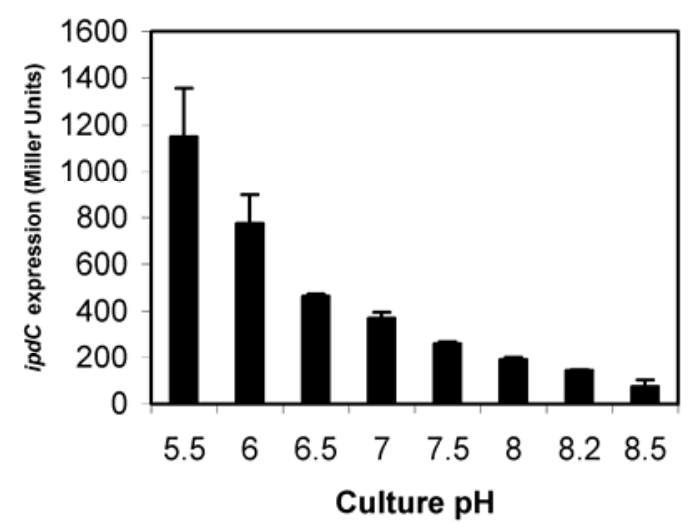

Fig. 4. Effect of $\mathrm{pH}$ levels in the range of 5.5 to 8.5 on the expression of the plasmid-encoded ipdC-gusA fusion pFAJ64 in Sp245. Sp245(pFAJ64) was grown to exponential growth phase (optical density at $600 \mathrm{~nm}=0.4$ ) in $\mathrm{LB}^{*}$ broth (Luria-Bertani broth supplemented with $2.5 \mathrm{mM} \mathrm{CaCl}_{2}$ and $2.5 \mathrm{mM} \mathrm{MgSO}_{4}$ ). Then, 3-ml samples from this culture were transferred to sterile test tubes, were buffered with morpholineethanesulfonic acid (MES) (pH 5.5, 6, or 6.5), $N$-tris(hydroxymethyl)methyl-2-aminoethanesulfonic acid (TES) (pH 7 or 8.2), $N$-2-hydroxyethylpiperazine- $N N^{\prime}$-2-ethanesulfonic acid (HEPES) (pH 7.5 and 8), or Tris ( $\mathrm{pH} 8.5$ ) to a final concentration of $30 \mathrm{mM}$, and were grown additionally for $5 \mathrm{~h}$ at $30^{\circ} \mathrm{C}$. Analyses for $\beta$ glucuronidase activity were as described (Jefferson 1987). Values are expressed in Miller units (Miller 1972) and represent the mean of three independent cultures, each assayed in duplicate. Error bars denote the standard deviations. 
site (TIS) was consistently observed at a C, located at $48 \mathrm{nu}$ cleotides upstream of the predicted translational start codon of ipdC (Fig. 6).

Next, in order to identify sequence motifs essential for expression and transcriptional regulation of ipdC by IAA and $\mathrm{pH}$ levels, a series of translational gusA fusions with successive 5' deletions in the region upstream of the ipdC gene was constructed. The exact size of the upstream fragment that was deleted in each of these fusions is depicted in Figure 6. The fusion plasmids were introduced into the wild-type strain Sp245 and the ipdC mutant FAJ0009 by mating, and the resulting strains were examined for GusA activity when grown under various physiological conditions. To determine the minimal region essential for ipdC expression, the gusA expression level of each promoter derivative was assessed in $\mathrm{Sp} 245$ when grown to the stationary growth phase (Fig. 7A).

The following observations were made. First, no expression was detected with the promoter derivatives pFAJ64.1, pFAJ64.3, pFAJ64.4, pFAJ64.5, pFAJ64.6, and pFAJ64.7. Second, deletion derivatives pFAJ64.11, pFAJ64.12, pFAJ64.14, pFAJ64.16, and pFAJ64.22 gave similar expression levels as pFAJ64, containing the entire promoter region, indicating that deletion of the region upstream from position -81 does not influence $i p d C$ transcription. As a consequence, the $5^{\prime}$ end of cis sequence elements required for complete activation of ipdC extends maximally to -81 . Third, in comparison with pFAJ64, a seven- to eightfold decrease in GusA activity was observed with deletion derivative pFAJ64.8 (sequence upstream from position -39 deleted), suggesting the binding of a putative activator protein at this position or more upstream from this position.

Next, we investigated the effect of exogenously added IAA and the culture medium $\mathrm{pH}$ level on ipdC expression in the deletion derivatives. For this, GusA activity was compared in exponential phase cells of the ipdC mutant FAJ0009, containing the ipdC promoter deletion derivatives, when grown in the absence or presence of exogeneously added IAA or after a shift to various $\mathrm{pH}$ levels. Similarly to what had been found for stationary grown cultures and confirming the defined minimal region required for ipdC expression, no activity was detected under any of these conditions for ipdC promoter deletion derivatives in which the sequence upstream from position -7 is deleted (data not shown). Upregulation of ipdC by IAA was observed for all of the other deletion derivatives except for pFAJ64.8. (Fig. 7B). In this deletion derivative, ipdC expression was again found to be drastically reduced as compared with pFAJ64, containing the entire promoter region, and additionally observed to be unaffected by the addition of IAA. Acid-induced expression of ipdC, however, was detected for all deletion derivatives showing ipdC expression (Fig. 7C).

Consequently, we examined the DNA sequence of the region between positions -39 and -81 for the presence of possible cisacting regulatory elements. Strikingly, between positions -58 and -38 , a perfect 8 -bp inverted repeat, separated by a 4-bp spacer (ATTGTTTC(GAAT)GAAACAAT), designated DS (for dyadic sequence), was found (Fig. 6). A previous examination of the region $5^{\prime}$ to the ipdC start codon has revealed the presence of the short sequence TGTCCC, designated SE1 (for sequence element 1), and reminiscent of the TGTCNC element or auxin-responsive element (AuxRe) of auxin-regulated genes in plants (Lambrecht et al. 1999). With respect to the identified TIS, this short sequence element is located at the positions -3 to -8 (Fig. 6). To verify the functionality of SE1 in ipdC transcription and to assess whether DS is a regulatory sequence involved in transcriptional activation of ipdC, these sequences were mutated by recombinant polymerase chain reaction (Fig. 6). Considering the fact that AuxRe elements in the $5^{\prime}$ region of auxin-responsive genes in plants are part of composite promoters and function together with a coupling element overlapping or adjacent to the TGTCNC site several nucleotides preceding SE1, here designated SE2 (Fig. 6), were additionally mutagenized. For this, the intact plasmid-borne PipdC-gusA translational fusion in pFAJ64a was used as a template and the oligonucleotide primers depicted in Table 1 were used to gen-

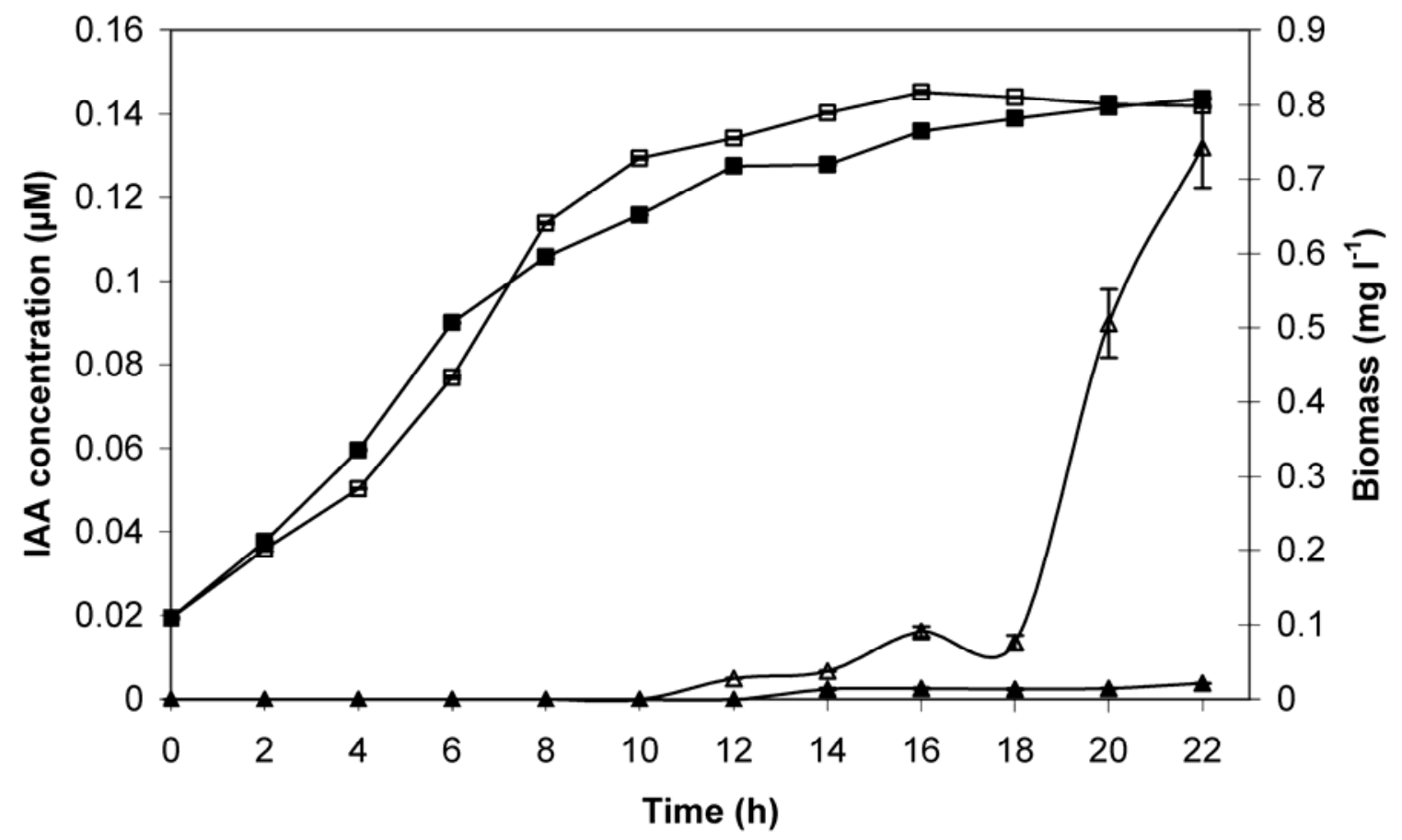

Fig. 5. Growth and kinetics of indole-3-acetic acid (IAA) production of Azospirillum brasilense Sp245 in a chemostat at pH 6.3 and 6.8. Cells were grown in Azospirillum minimal medium. Periodically, samples were taken in triplicate to follow the growth and to measure the IAA concentration in the growth medium. Values represent the mean of three samples. Error bars denote the standard deviation. Similar results were obtained in independent experiments. Squares, biomass (cell dry weight in milligrams per liter); triangles, IAA concentration $(\mu \mathrm{M})$; open symbols, $\mathrm{pH}$ 6.3; solid symbols, $\mathrm{pH} 6.8$. 
erate four constructs, one with a mutated SE1 sequence (pFAJ64a-MUT1), one with a mutated SE2 (pFAJ64a-MUT2), and two with a mutated DS (pFAJ64a-MUT3 and pFAJ64aMUT4) (Fig. 6). This set of mutated promoter-gusA fusions was then cloned in the broad host range plasmid pLAFR3, yielding pFAJ64-MUT1, pFAJ64-MUT2, pFAJ64-MUT3, and pFAJ64-MUT4 and was mobilized to A. brasilense Sp245 and the ipdC mutant FAJ0009. The resulting strains were then examined for GusA activity in the stationary growth phase (Fig. 8A), when cultured in the absence and presence of exogenously added IAA (Fig. 8B), or switched to various pHs (Fig. 8C). No GusA activity could be measured, under all conditions tested, with strains that carried the reporter gene fused with the promoters containing mutations in SE1 and SE2, indicating that these nucleotides at the region centered around position -20 and between positions -2 and -8 are strictly required for ipdC transcription. The point mutations 3 and 4 in the DS resulted in a six- to eightfold reduction in ipdC expression under all conditions studied, supporting the hypothesis that this sequence motif functions as a recognition site for an activator protein. Furthermore, ipdC expression directed by these two mutated DS was no longer found to be upregulated by IAA (Fig. 8B), suggesting that the putative positive regulatory protein binding to DS responds to IAA. Acid-induced expression of ipdC, however, was found to be unaffected by the substitutions in DS (Fig. 8C).

\section{Effect of insertional inactivation}

of $i a a C$ on ipdC expression and IAA production.

As described above, iaaC is organized in an operon together with ipdC. To analyze a possible role of iaaC in ipdC transcription, the ipdC-gusA fusion pFAJ64 was transferred into the $i a a C$ insertion mutant FAJ0010 and GusA activity was determined when grown under various physiological conditions.
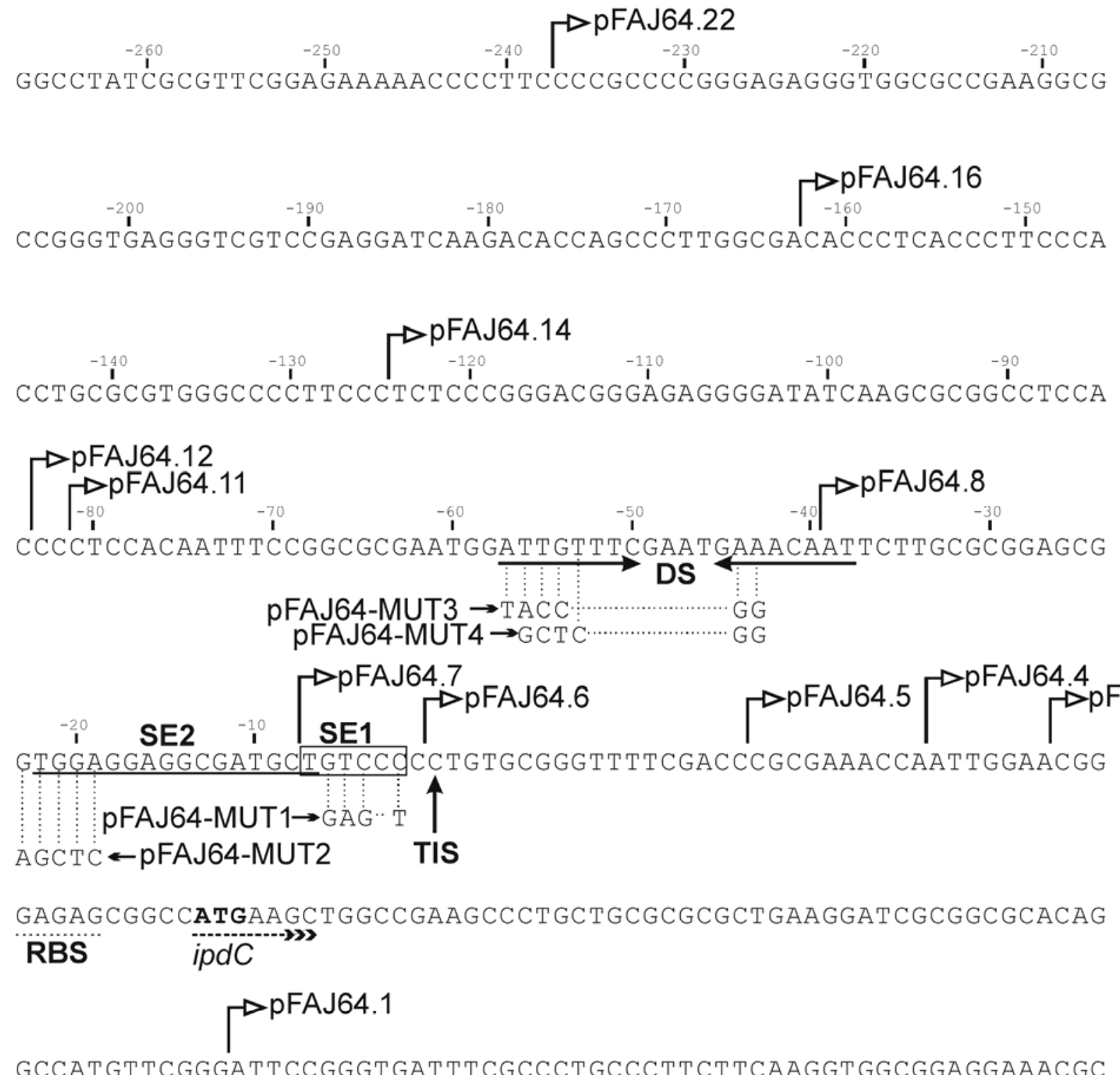

Fig. 6. Nucleotide sequence and features of the $5^{\prime}$ region of ipdC. The $5^{\prime}$ region shown is present in the original promoter-gusA fusion, pFAJ64. The ipdC start codon is indicated in boldface. The transcription initiation site (TIS), determined by primer extension analysis, is indicated by a vertical up arrow. The distinct ipdC promoter-gusA derivatives containing an upstream deletion are named above the nucleotide sequence. The $5^{\prime}$ end of the deleted promoter region in each derivative is indicated by a vertical angled arrow. The DNA sequence of the TGTCNC element, designated SE1, is boxed; the inverted repeat (DS) is indicated by opposite underlining arrows. The nucleotides that were altered by site-directed mutagenesis in the sequence elements SE1, SE2, and DS in the ipdC promoter-gusA derivatives pFAJ64MUT1, pFAJ64MUT2, pFAJ64MUT3, and pFAJ64MUT4, respectively, are shown below the nucleotide sequence. Numbering above the sequence is relative to the TIS. 
The conditions tested were cells grown to stationary phase, IAA-induced and uninduced exponentially grown cells, and exponentially grown cells at $\mathrm{pH} 5.5,7$, or 8.5. Under all the conditions tested, the iaaC mutant had growth rates and biomass yields similar to those of the parent strain Sp245, and no difference in ipdC expression in the wild type and FAJ0010 could be observed (data not shown). However, a clear difference could be detected in the IAA production levels of both strains, with the $i a a C$ insertion mutant having a clearly enhanced IAA production capacity as compared with the parental strain. When cultured in a chemostat at a constant $\mathrm{pH}$ of 6.3 or 6.8 , IAA concentrations measured at the stationary growth phase in the iaaC mutant culture were 5.5- to sixfold higher as compared with the wild-type culture (data not shown). These observations indicate that the protein encoded by ia $C$ is a repressor of auxin production. The gene was therefore named iaaC, for encoding an IAA biosynthesis controlling protein.

\section{DISCUSSION}

So far, the A. brasilense ipdC gene is the only bacterial gene reported to be IAA inducible (Vande Broek et al. 1999). In this work, we performed a detailed study of the promoter region, in order to identify the promoter sequence elements required for ipdC expression as well as putative additional cis elements essential for the specific transcriptional regulation in response to IAA.

Examination of progressive deletions of the $5^{\prime}$ flanking region of the ipdC gene indicated that the $5^{\prime}$ end of the cis-acting elements required both for full promoter activation and for the IAA-mediated upregulation of ipdC maximally extends to position -81 relative to the determined transcription initiation site. Within this upstream region, located between positions 58 and -38 , a perfect two 8-bp inverted repeat separated by a 4-bp spacer was identified. Site-directed mutagenesis of this dyadic sequence as well as deletion demonstrated that this element, hereafter named bacterial auxin-regulated element, is required for full activation of the ipdC promoter and, additionally, is essential for its IAA inducibility. The expression data and the position of this proximal element centered at -48 suggested that it functions as an activator-binding site, allowing direct contact with the RNA polymerase holoenzyme (Gralla and Collado-Vides 1996). Interestingly, using gel mobility shift experiments (Yagi et al. 2001) demonstrated the binding of two unidentified proteins to an identical inverted repeat found in the $5^{\prime}$ region of the ipdC gene of the closely related Azospirillum lipoferum.

At present, the mechanism responsible for the enhanced activity of an activator protein in response to IAA is not known. Possibly the gene encoding the activator protein is an IAA-regulated gene itself. Many genes encoding regulatory proteins involved in auxin-mediated gene expression in plants, such as, for example, the Aux/IAA genes, are themselves regulated by auxin (Hagen and Guilfoyle 2002). Alternatively, the activator might be an IAA-binding protein. The conjugation of IAA to many classes of biomolecules including peptides (Bialek and Cohen 1986) and proteins (Walz et al. 2002) has been reported. Also, for instance in many metabolic operons, the binding of low molecular weight compounds to regulatory proteins causes dissociation of the proteins from their target promoter regions or, on the contrary, increases its binding affinity to DNA (Lewis et al. 1996; Schreiber et al. 2000). The binding of IAA to the activator could be a means to modulate the protein conformation, thereby changing its capacity to bind to its recognition sequence. Finally, IAA might be a signal molecule that, when bound to its receptor protein, alters its stability. Protein sta-

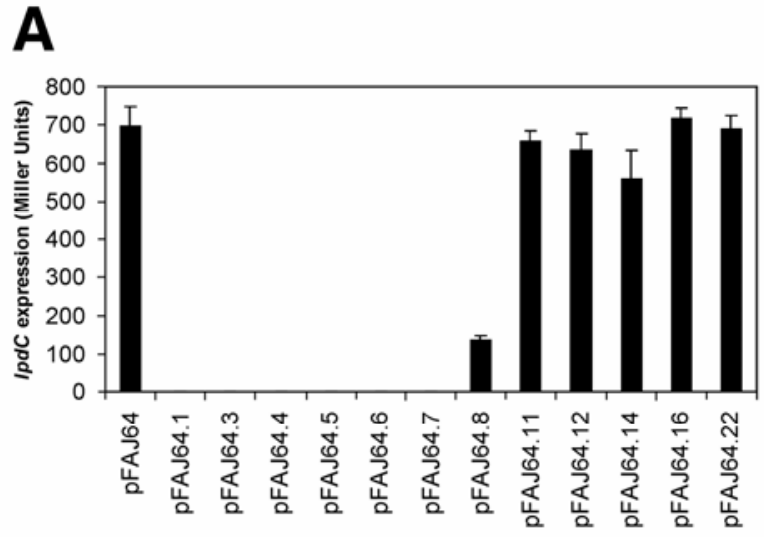

B

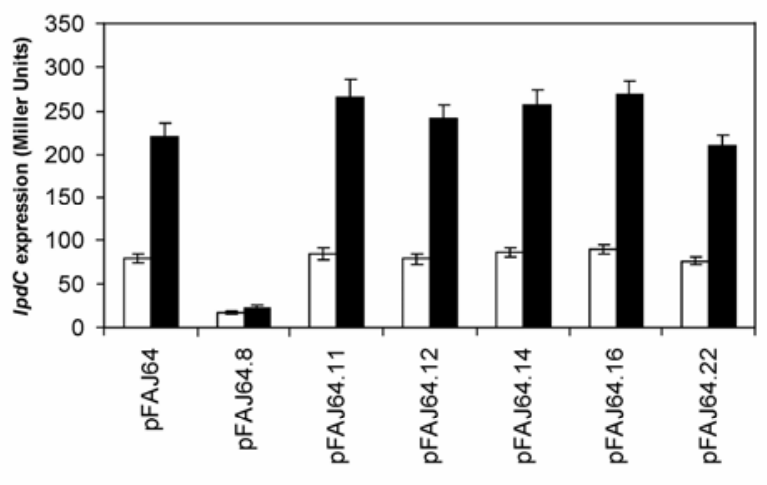

C

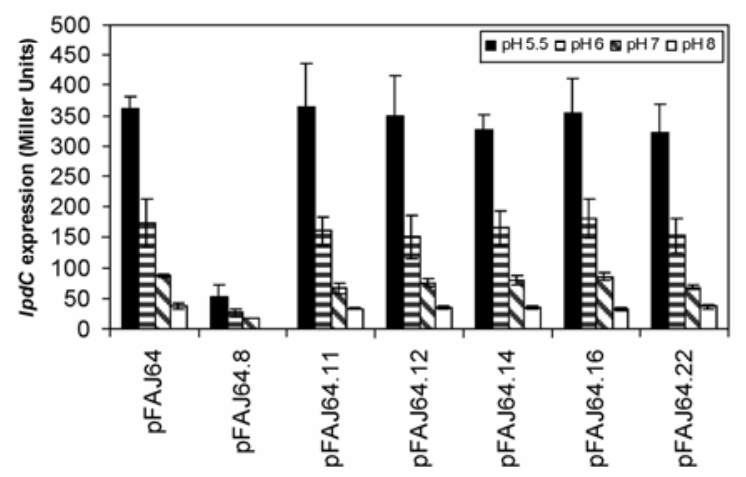

Fig. 7. Levels of GusA activity of the plasmid-encoded ipdC-gusA fusion pFAJ64 and its promoter deletion derivatives. A, $\beta$-glucuronidase (GUS) activities in stationary growth phase cultures of Sp245 containing the distinct promoter deletion derivatives of pFAJ64. B, Effect of exogeneously added indole-3-acetic acid (IAA) on the GUS activities. Cultures of the ipdC mutant FAJ0009 containing the distinct promoter deletion derivatives of pFAJ64 were grown to exponential growth phase (optical density at $600 \mathrm{~nm}\left[\mathrm{OD}_{600}\right]=0.4$ ) in $\mathrm{LB}^{*}$ broth (Luria-Bertani broth supplemented with $2.5 \mathrm{mM} \mathrm{CaCl}_{2}$ and $2.5 \mathrm{mM} \mathrm{MgSO}_{4}$ ). Then, from each culture, six 3-ml samples were transferred to sterile test tubes. Three test tubes of each series were supplemented with IAA to a final concentration of $1 \mathrm{mM}$ (solid bars); to the remaining test tubes no IAA was added (open bars). After $3.5 \mathrm{~h}$ of additional growth at $30^{\circ} \mathrm{C}$, GUS activity was assayed. $\mathbf{C}$, Effect of $\mathrm{pH}$ of the culture medium on the GUS activities. Cultures of FAJ0009 containing the distinct promoter deletion derivatives of pFAJ64 were grown to exponential growth phase $\left(\mathrm{OD}_{600}=\right.$ $0.4)$ in LB* broth. Then, 3-ml samples from each culture were transferred to sterile test tubes, buffered with morpholineethanesulfonic acid (MES) (pH 5.5 and 6), $N$-tris(hydroxymethyl)methyl-2-aminoethanesulfonic acid (TES) (pH 7), or $N$-2-hydroxyethylpiperazine- $N$ '-2-ethanesulfonic acid (HEPES) ( $\mathrm{pH} 8$ ) and were grown additionally for $5 \mathrm{~h}$ at $30^{\circ} \mathrm{C}$. Values represent the mean of three independent cultures, each assayed in duplicate. Error bars denote the standard deviations. 


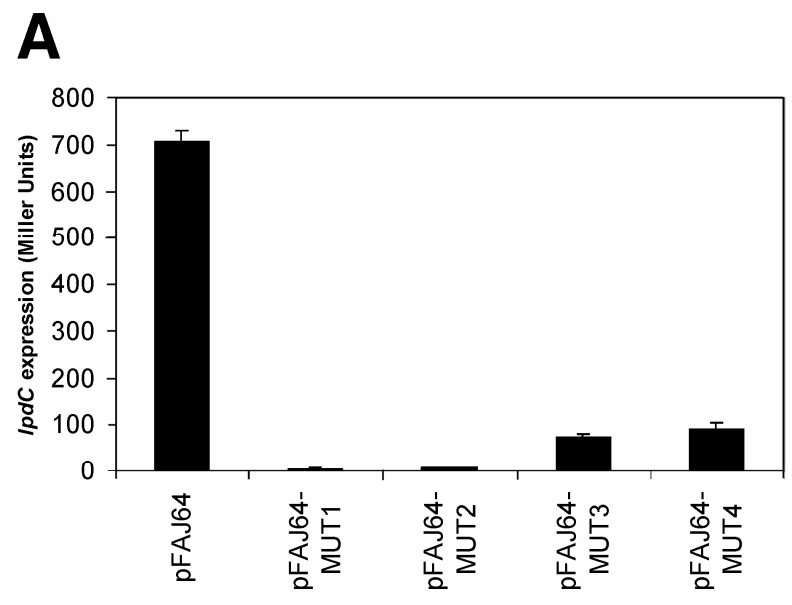

B

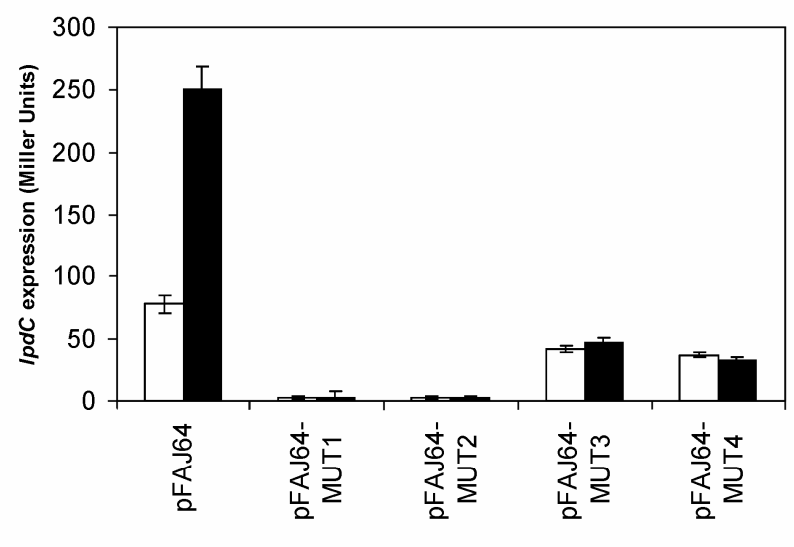

C

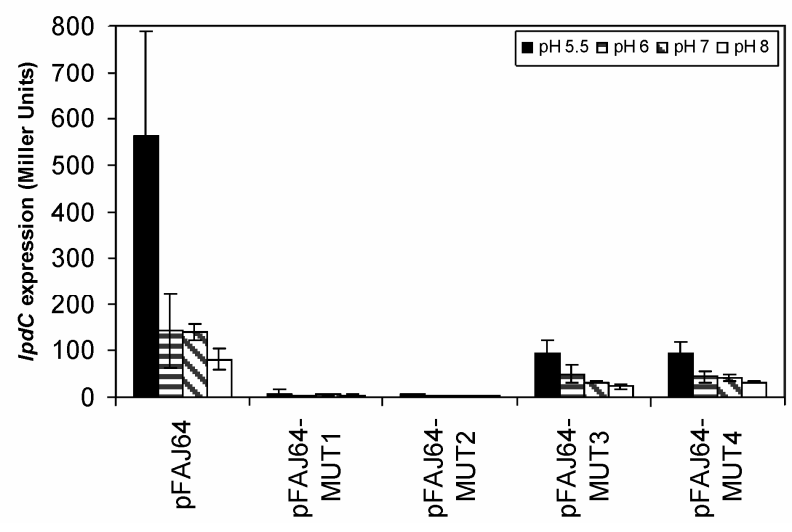

bility and degradation is a recurrent theme in auxin signal transduction in plants (Dharmasiri and Estelle 2002; Hellmann and Estelle 2002; Kepinski and Leyser 2002).

The region located between -2 to -23 was shown to be strictly required for ipdC expression, as point mutations within this region completely abolished ipdC expression. Based on its position, it can be anticipated that this region contains the RNA polymerase binding site. Inspection of the DNA sequence, however, did not reveal similarity to any typical bacterial promoter sequence. The TGTCNC element, resembling the AuxRe found in IAA-inducible plant promoters and previously supposed to be involved in the IAA-mediated induction of the A. brasilense ipdC gene, is also contained within this region (Lambrecht et al. 1999). However, as mutations in this element reduced expression of the ipdC gene expression level to background level, we were not able to evaluate whether this hypothetical AuxRe is involved in the inducing effect of IAA, and a possible role of this element, besides the dyadic sequence, in auxin-mediated expression cannot be ruled out.

Upon examination of the effect of different stress stimuli on ipdC expression, it was observed that the induction of ipdC is $\mathrm{pH}$-dependent and maximal at acidic conditions. It is wellknown that proton extrusion through membranes of root cells results in the acidification of the rhizosphere and is a major mechanism in the mobilization of minerals by plants. In addition, enhanced proton efflux of roots of several major crop plants upon Azospirillum inoculation has been reported (Bashan 1990; Carrillo et al. 2002). As ipdC expression and IAA production are enhanced at acidic $\mathrm{pH}$ levels, the acidic rhizo-

Fig. 8. Effect of the specific mutations in the $5^{\prime}$ noncoding region of ipdC on the induction of the ipdC-gusA fusion. A, $\beta$-glucuronidase (GUS) activities in stationary growth phase cultures of Sp245 containing the distinct promoter derivatives of pFAJ64. B, Effect of exogeneously added indole-3-acetic acid (IAA) on the GUS activities. Cultures of ipdc mutant FAJ0009 containing the distinct promoter derivatives of pFAJ64 were grown to exponential growth phase (optical density at $600 \mathrm{~nm}\left(\mathrm{OD}_{600}\right)=0.4$ ) in LB* broth (LuriaBertani broth supplemented with $2.5 \mathrm{mM} \mathrm{CaCl}_{2}$ and $2.5 \mathrm{mM} \mathrm{MgSO}_{4}$ ). Then, from each culture, six 3-ml samples were transferred to sterile test tubes. Three test tubes of each series were supplemented with IAA to a final concentration of $1 \mathrm{mM}$ (side bars); no IAA was added to the remaining test tubes (open bars). After $3.5 \mathrm{~h}$ of additional growth at $30^{\circ} \mathrm{C}$, GUS activity was assayed. C, Effect of the $\mathrm{pH}$ level of the culture medium on the GUS activities. Cultures of FAJ0009 containing the distinct promoter deletion derivatives of pFAJ64 were grown to exponential growth phase $\left(\mathrm{OD}_{600}=\right.$ 0.4 ) in LB* broth. Then, 3-ml samples from each culture were transferred to sterile test tubes, buffered with morpholineethanesulfonic acid (MES) (pH 5.5 and 6 ), $N$-tris(hydroxymethyl)methyl-2-aminoethanesulfonic acid (TES) (pH 7), or $N$-2-hydroxyethylpiperazine- $N N^{\prime}$-2-ethanesulfonic acid (HEPES) $(\mathrm{pH} 8)$ and were grown additionally for $5 \mathrm{~h}$ at $30^{\circ} \mathrm{C}$. Values represent the mean of three independent cultures, each assayed in duplicate. Error bars denote the standard deviations.

Table 1. Primers used for site-directed mutagenesis

\begin{tabular}{|c|c|c|c|}
\hline Primer $^{\mathrm{a}}$ & Sequence $\left(5^{\prime} \text { to } 3^{\prime}\right)^{b}$ & Site $^{\mathrm{c}}$ & Position $^{d}$ \\
\hline IPDCMUT1 (FW) & GGTTGGAGGAGGCGATGCGAGCTCCCTGTGCGGGTTTTCGACC & $S a c \mathrm{I}$ & -24 to +18 \\
\hline IPDCMUT1 (BW) & GGTCGAAAACCCGCACAGGGAGCTCGCATCGCCTCCTCCAACC & $S a c \mathrm{I}$ & \\
\hline IPDCMUT2 (FW) & 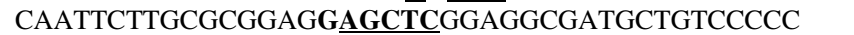 & $S a c \mathrm{I}$ & -41 to -3 \\
\hline IPDCMUT2 (BW) & GGGGGACAGCATCGCCTCCGAGCTCCTCCGCGCAAGAATTG & $S a c \mathrm{I}$ & \\
\hline IPDCMUT3 (FW) & CCGGCGCGAATGGTACCTTTCGAATGGGACAATTCTTGCGC & KpnI & -70 to -30 \\
\hline IPDCMUT3 (BW) & GCGCAAGAATTGTCCCATTCGAAAGGTACCATTCGCGCCGG & KpnI & \\
\hline IPDCMUT4 (FW) & CCGGCGCGAATGGAGCTCTTCGAATGGGACAATTCTTGCGCG & $\mathrm{SacI}$ & -70 to -29 \\
\hline IPDCMUT4 (BW) & 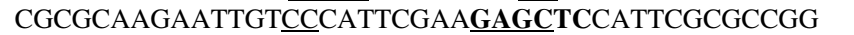 & $S a c \mathrm{I}$ & \\
\hline
\end{tabular}

${ }^{\mathrm{a}} \mathrm{FW}=$ forward primer, $\mathrm{BW}=$ backward primer.

${ }^{\mathrm{b}}$ The underlined nucleotides are those that differ from the original sequence. The introduced KpnI or SacI restrictions sites are indicated in bold.

${ }^{\mathrm{c}}$ Introduced restriction recognition sites.

${ }^{\mathrm{d}}$ Numbering is relative to the identified transcription start site. 
sphere probably favors IAA biosynthesis by azospirilla in the vicinity of the roots, resulting in the observed root growth promotion. The promoter deletion analysis performed in this work shows that all fusions displaying expression of the ipdC gene are still $\mathrm{pH}$-inducible. Also, mutation of the bacterial auxin-regulated element did not affect the $\mathrm{pH}$ inducibility, suggesting that $\mathrm{pH}$ - and IAA-mediated upregulation occur independently and that the bacterial auxin-responsive element does not confer $\mathrm{pH}$ inducibility. Possibly, an alternative sigma factor whose expression or accumulation, or both, is itself acid-regulated is responsible for the $\mathrm{pH}$ response. In E. coli and Shigella species, some low $\mathrm{pH}$-inducible acid resistance systems have been shown to be dependent on the alternative sigma factor $\sigma^{\mathrm{s}}$, encoded by rpoS and known to be a critical regulator of stationary phase physiology and general stress response (HenggeAronis 2002; Small et al. 1994). Similarly, in Salmonella typhimurium, $\sigma^{\mathrm{s}}$ is an acid shock protein and controls the expression of other acid shock proteins (Lee et al. 1995). The acid shock induction of $\sigma^{\mathrm{s}}$ appears to be controlled in E. coli by the response regulator RssB (Becker et al. 1999; Klauck et al. 2001) and in S. typhimurium by the homologous protein MviA (Moreno et al. 2000), which have been shown to regulate proteolysis of $\sigma^{\mathrm{s}}$ by ClpXP after sensing acid stress (Jenal and Hengge-Aronis 2003). Interestingly, expression of the Erwinia herbicola 299R and Pseudomonas putida GR12-2 ipdC genes is controlled by RpoS (Brandl et al. 2001; Patten and Glick 2002a). However, although rpoS is widespread in $\beta$ - and $\gamma$-proteobacteria, $\operatorname{rpoS}$ is not present in the genome sequences of $\alpha$ proteobacteria such as Caulobacter crescentus and several rhizobia and Rickettsia species. Also, various attempts to identify an rpoS gene in A. brasilense, a member of the $\alpha$-proteobacteria, have not been successful (P. Gysegom, personal communication). Besides rpoS, other sigma factors have also been implicated in acid tolerance response (Gaidenko and Price 1998; Ferreira et al. 2001; Wiedmann et al. 1998).

Sequence analysis of the region downstream of ipdC revealed the presence of an ORF designated iaaC. Northern analysis demonstrated that this ORF is located in an operon with ipdC but is additionally transcribed from its own promoter. The translated amino acid sequence is homologous to prokaryotic proteins like the E. coli SCRP-27A protein, the Yersinia pestis Elb2 protein, and hypothetical proteins from Pseudomonas aeruginosa (AAG08630) and Salmonella enterica subsp. enterica serovar Typhi (CAD07844) as well as with eukaryotic proteins like the human HES1 protein and the zebrafish ES1 protein. However, the function of these homologs is still not known. The overall similarity between these prokaryotic and eukaryotic proteins is high, and strongly conserved regions are present, indicating functional importance and suggesting that the proteins are involved in a basic function common to both prokaryotic and eukaryotic cells.

In this work, we demonstrated that the A. brasilense iaaC gene is involved in repression of IAA biosynthesis but has no effect on ipdC expression under all conditions tested. IaaC and the above-described homologs belong to the DJ-1/PfpI family, based on the presence of specific protein domains. This DJ-1/PfpI superfamily hosts many proteins with a wide range of functions, including protein chaperones, catalases, proteases, and RNA-binding proteins as well as many hypothetical proteins. However, despite its large distribution in a variety of proteins, the exact function of the specific protein domain is still not known. Recently, an extensive sequence homology analysis between the members of the superfamily grouped all the IaaC homologs as a separate cluster within this superfamily (Bandyopadhyay and Cookson 2004). This cluster is most similar to a second group of proteins of the DJ-1/PfpI family including E. coli Hsp31, a stress-inducible molecular chaperone (Sastry et al. 2002), and a Saccharomyces cerevisiae protein, YDR533Cp (Wilson et al. 2004). The expression of the latter protein is upregulated when yeast cells enter the stationary state as a result of carbon starvation (de Nobel et al. 2001), during heat shock, or in the presence of thermally misfolded proteins (Trotter et al. 2002). Reportedly, this protein is also likely to function as a chaperone needed for protein folding in stress situations (Wilson et al. 2004). Therefore, it is not unlikely that IaaC might possess a function similar to Hsp31 and YDR533Cp, as iaaC expression in A. brasilense is maximized in stress conditions such as stationary phase (Vande Broek et al. 1999) and low pH and as IaaC clearly does not influence ipdC transcription. Besides its chaperone activity, E. coli Hsp31 also has protease activity (Lee et al. 2003). A putative catalytic triad containing adjacent $\mathrm{C} / \mathrm{H}$ residues and possibly controlling this activity was identified in Hsp31. However, this signature sequence is missing in the IaaC homologs.

In conclusion, the data presented in this and previous studies show that IAA biosynthesis in A. brasilense is a very complex, strictly regulated process, similar to the complexity observed in plants. Elements for the existence of a bacterial auxin signal transduction pathway are given, allowing the bacteria to control the production of a molecule, which plays a crucial role in the growth of the host plant.

\section{MATERIALS AND METHODS}

\section{Bacterial strains and growth conditions.}

The strains and plasmids used in this study are described in Table 2. LB broth (Sambrook et al. 1989) was used to culture E. coli at $37^{\circ} \mathrm{C}$. Azospirillum spp. were grown in LB* or in Azospirillum minimal medium (MMAB) (Vanstockem et al. 1987 ) at $30^{\circ} \mathrm{C}$. For solid media, $15 \mathrm{~g}$ of agar per liter was added. Both for Azospirillum spp. and E. coli, antibiotics were used when appropriate in the following concentrations: ampicillin $\left(100 \mu \mathrm{g} \mathrm{ml}^{-1}\right)$, kanamycin $\left(25 \mu \mathrm{g} \mathrm{ml} \mathrm{m}^{-1}\right)$, and tetracycline $\left(10 \mu \mathrm{g} \mathrm{ml}^{-1}\right)$. Buffering of the growth medium was achieved by the addition of $30 \mathrm{mM}$ HEPES ( $N$-2-hydroxyethylpiperazine- $N^{\prime}$-2-ethanesulfonic acid) (pH range 6.8 to 8.2 ) (Sigma, St. Louis), $30 \mathrm{mM}$ MOPS (morpholinepropanesulfonic acid) (pH range 6.5 to 7.9 ) (Sigma), or $30 \mathrm{mM}$ MES (morpholineethanesulfonic acid) ( $\mathrm{pH}$ range 5.5 to 6.7) (Sigma). The effect of osmotic stress on ipdC expression was assayed by adding $\mathrm{NaCl}$ up to $6 \%$ and PEG4000 up to $15 \%$ to the LB* growth medium. Culturing at various oxygen tensions was achieved as described previously (Vande Broek et al. 1996). Induction of $i p d C$ by IAA was evaluated in exponential phase cultures of FAJ0009 as described previously (Vande Broek et al. 1999).

\section{DNA manipulations and nucleotide sequencing.}

For plasmid isolation, restriction enzyme digestion, ligation, and transformation of $E$. coli, standard techniques were used (Sambrook et al. 1989). Plasmids were transferred to A. brasilense by triparental mating as described previously, with pRK2073 as a helper plasmid (Vanstockem et al. 1987). For DNA sequence analysis, recombinant plasmids were purified with the GFX micro plasmid prep kit (Amersham Biosciences, Piscataway, NJ, U.S.A.). DNA sequencing was accomplished on an automated sequencer (ALF or ALFexpress; Amersham Biosciences) by using the AutoRead sequencing kit (Amersham Biosciences) and fluorescein or Cy5-labeled universal oligonucleotide primers. The nucleotide sequences of the $A$. brasilense gltX and iaaC genes are in the DDBJ, EMBL, and the GenBank nucleotide sequence databases (U17699 and AY608698, respectively). 
Database searching and multiple alignments.

Database searches were performed using the programs BLASTX and BLASTP (Altschul et al. 1990). The ClustalW algorithm (Thompson et al. 1994) was used for multiple protein alignments, and the alignment layout was prepared by the Genedoc program (Nicholas et al. 1997).

\section{GUS assays.}

Quantitative analysis of GUS activity in bacterial cultures was carried out in microtiter plates, using the GUS extraction buffer and $p$-nitrophenyl- $\beta$-D-glucuronide as substrate (Jefferson 1987). Activity in each culture was always assayed in duplicate. Units are as described by Miller (1972) for $\beta$-galactosidase activity and represent the mean of at least three (independent) cultures.

\section{IAA measurements.}

To measure the IAA production capacity of an A. brasilense strain, cells were grown in a batch fermentation culture. For this, a chemostat of 6-liter capacity (Bioflow 3000; New

Table 2. Strains and plasmids

\begin{tabular}{|c|c|c|}
\hline Strain or plasmid & Relevant characteristics & Reference or source \\
\hline \multicolumn{3}{|l|}{$\begin{array}{l}\text { Strains } \\
\end{array}$} \\
\hline \multicolumn{3}{|l|}{ Escherichia coli } \\
\hline DH5 $\alpha$ & hsdR17 endA1 thi-1 gyrA96 relA1 recA1 supE44 $\Delta l a c U 169($ (\$0lacZAM15) & Sambrook et al. 1989 \\
\hline HB101 & $\mathrm{F}^{-} h s d S 20\left(\mathrm{r}_{\mathrm{B}}^{-} \mathrm{m}_{\mathrm{B}}^{-}\right)$recA13 ara-14 proA2 lacY1 galK2 rpsL20 xyl-5 supE44 & Sambrook et al. 1989 \\
\hline S17.1 & RP4-2-Tc:: Mu-Km::Tn7 $\mathrm{Tra}^{+}$pro thi hsdR recA $\mathrm{Sm}^{\mathrm{r}}$ & Simon et al. 1983 \\
\hline S17.1::Tn5 & S17.1 derivative containing $\mathrm{Tn} 5$ in the chromosome, $\mathrm{Km}^{\mathrm{r}}$ & Bozouklian and Elmerich 1986 \\
\hline \multicolumn{3}{|l|}{ Azospirillum brasilense } \\
\hline Sp245 & Wild-type strain, isolated from surface-sterilized wheat roots (Brazil) & Baldani et al. 1986 \\
\hline FAJ0009 & Sp245 ipdC::Tn5 & Costacurta et al. 1994 \\
\hline FAJ010 & Sp245 iaaC::Tn5 & This study \\
\hline \multicolumn{3}{|l|}{ Plasmids } \\
\hline pUC18/19 & Cloning vector, ColE1 replicon, lacIPOZ $^{+}, \mathrm{Ap}^{\mathrm{r}}$ & Yanisch-Perron et al. 1985 \\
\hline pLAFR3 & IncP1 broad host range plasmid, containing the pUC8 multiple cloning site, $\mathrm{Tc}^{\mathrm{r}}$ & Staskawicz et al. 1987 \\
\hline pSUP202 & pBR325 containing RP4 Mob site, suicide vector for A. brasilense, $\mathrm{Cm}^{\mathrm{r}}, \mathrm{Tc}^{\mathrm{r}}, \mathrm{Ap}^{\mathrm{r}}$ & Simon et al. 1983 \\
\hline pRK2073 & Helper plasmid for triparental conjugations, $\mathrm{Mob}^{+}, \mathrm{Tra}^{+}, \mathrm{ColE} 1$ replicon, $\mathrm{Sm}^{\mathrm{r}}$ & Figurski and Helinski 1979 \\
\hline pUC19-6.5A & 6.5-kb EcoRI fragment, carrying the ipdC and the iaaC gene, in pUC19 & Costacurta et al. 1994 \\
\hline pCMPG9250 & 4.3-kb $B g l I I-B a m H I$ fragment, carrying the entire $i a a C$ gene, in pSUP202 & This study \\
\hline pCMPG9250-Tn5a & pCMPG9250 derivative, carrying a $\mathrm{Tn} 5$ insertion in the $\mathrm{ia} a \mathrm{C}$ gene & This study \\
\hline pFAJ64a & Wild-type ipdC-gusA translational fusion in pUC18, containing $350 \mathrm{bp}$ of the ipdC promoter & Vande Broek et al. 1999 \\
\hline pFAJ64 & Wild-type ipdC-gusA translational fusion in pLAFR3, containing $350 \mathrm{bp}$ of the ipdC promoter & Vande Broek et al. 1999 \\
\hline pFAJ64a.22 & pFAJ64a derivative, deletion of the ipdC promoter region upstream of position -237 & This study ${ }^{\mathrm{a}}$ \\
\hline pFAJ64a.16 & pFAJ64a derivative, deletion of the ipdC promoter region upstream of position -162 & This study \\
\hline pFAJ64a.14 & pFAJ64a derivative, deletion of the ipdC promoter region upstream of position -124 & This study \\
\hline pFAJ64a. 12 & pFAJ64a derivative, deletion of the ipdC promoter region upstream of position -83 & This study \\
\hline pFAJ64a.11 & pFAJ64a derivative, deletion of the ipdC promoter region upstream of position -81 & This study \\
\hline pFAJ64a.8 & pFAJ64a derivative, deletion of the ipdC promoter region upstream of position -39 & This study \\
\hline pFAJ64a.7 & pFAJ64a derivative, deletion of the ipdC promoter region upstream of position -7 & This study \\
\hline pFAJ64a.6 & pFAJ64a derivative, deletion of the ipdC promoter region upstream of position 0 & This study \\
\hline pFAJ64a.5 & pFAJ64a derivative, deletion of the ipdC promoter region upstream of position +18 & This study \\
\hline pFAJ64a.4 & pFAJ64a derivative, deletion of the ipdC promoter region upstream of position +28 & This study \\
\hline pFAJ64a.3 & pFAJ64a derivative, deletion of the ipdC promoter region upstream of position +35 & This study \\
\hline pFAJ64a.1 & pFAJ64a derivative, deletion of the ipdC promoter region upstream of position +107 & This study \\
\hline pFAJ64.22 & pFAJ64 derivative, deletion of the ipdC promoter region upstream of position -237 & This study \\
\hline pFAJ64.16 & pFAJ64 derivative, deletion of the ipdC promoter region upstream of position -162 & This study \\
\hline pFAJ64.14 & pFAJ64 derivative, deletion of the ipdC promoter region upstream of position -124 & This study \\
\hline pFAJ64.12 & pFAJ64 derivative, deletion of the ipdC promoter region upstream of position -83 & This study \\
\hline pFAJ64.11 & pFAJ64 derivative, deletion of the ipdC promoter region upstream of position -81 & This study \\
\hline pFAJ64.8 & pFAJ64 derivative, deletion of the ipdC promoter region upstream of position -39 & This study \\
\hline pFAJ64.7 & pFAJ64 derivative, deletion of the ipdC promoter region upstream of position -7 & This study \\
\hline pFAJ64.6 & pFAJ64 derivative, deletion of the ipdC promoter region upstream of position 0 & This study \\
\hline pFAJ64.5 & pFAJ64 derivative, deletion of the ipdC promoter region upstream of position +18 & This study \\
\hline pFAJ64.4 & pFAJ64 derivative, deletion of the ipdC promoter region upstream of position +28 & This study \\
\hline pFAJ64.3 & pFAJ64 derivative, deletion of the ipdC promoter region upstream of position +35 & This study \\
\hline pFAJ64.1 & pFAJ64 derivative, deletion of the ipdC promoter region upstream of position +107 & This study \\
\hline \multirow[t]{2}{*}{ pFAJ64a-MUT1 } & pFAJ64a derivative, mutated ipdC promoter region created with primers & \\
\hline & IPDCMUT1(FW/BW), mutation in SE1 & This study \\
\hline \multirow[t]{2}{*}{ pFAJ64a-MUT2 } & pFAJ64a derivative, mutated ipdC promoter region created with primers & \\
\hline & IPDCMUT2(FW/BW), mutation in SE2 & This study \\
\hline \multirow[t]{2}{*}{ pFAJ64a-MUT3 } & pFAJ64a derivative, mutated $i p d C$ promoter region created with primers & \\
\hline & IPDCMUT3(FW/BW), mutation in DS & This study \\
\hline \multirow[t]{2}{*}{ pFAJ64a-MUT4 } & pFAJ64a derivative, mutated ipdC promoter region created with primers & \\
\hline & IPDCMUT4(FW/BW), mutation in DS & This study \\
\hline \multirow{2}{*}{ pFAJ64-MUT1 } & pFAJ64 derivative, mutated ipdC promoter region created with primers & \\
\hline & IPDCMUT1(FW/BW), mutation in SE1 & This study \\
\hline \multirow[t]{2}{*}{ pFAJ64-MUT2 } & pFAJ64 derivative, mutated ipdC promoter region created with primers & \\
\hline & IPDCMUT2(FW/BW), mutation in SE2 & This study \\
\hline \multirow[t]{2}{*}{ pFAJ64-MUT3 } & pFAJ64 derivative, mutated ipdC promoter region created with primers & \\
\hline & IPDCMUT3(FW/BW), mutation in DS & This study \\
\hline \multirow{2}{*}{ pFAJ64-MUT4 } & pFAJ64 derivative, mutated ipdC promoter region created with primers & \\
\hline & IPDCMUT4(FW/BW), mutation in DS & This study \\
\hline
\end{tabular}

\footnotetext{
${ }^{a}$ The coordinates of the positions in the ipdC promoter region are indicated with respect to the identified ipdC transcription initiation site.
} 
Brunswick Scientific, Edison, NJ, U.S.A.) was used. The growth medium used was MMAB (Vanstockem et al. 1987). The fermentation temperature was set at $30^{\circ} \mathrm{C}$, dissolved oxygen (DO) at $3 \%$, and the aeration rate at 0.1 liter per min. The $\mathrm{pH}$ was maintained at 6.3 or 6.8 and was automatically adjusted with a $\mathrm{H}_{2} \mathrm{SO}_{4}$ solution $(0.5 \mathrm{M})$, according to the measured $\mathrm{pH}$ values ( $\mathrm{pH}$ probe Ingold). The speed of agitation was automatically regulated to keep the DO level at the setpoint. In addition to the fermentor's internal controller, a bioprocess software (AFS-BioCommand, New Brunswick Scientific) was used to supervise the process $(\mathrm{pH}$, temperature, DO, and air flow). Samples were taken at regular time intervals and were analyzed for the IAA concentration in the supernatant, using gas chromatography with on-line mass spectrometry as described by Prinsen and associates (2000). All data shown are the average of at least two replicates. Biomass concentration (defined as cell dry weight [milligram] per milliliter of culture broth) was determined by weighting dried cells with a microbalance (Mettler Toledo, Greifensee, Switzerland), as described by Wang and Lee (1997).

\section{RNA isolation and transcriptional analysis.}

Total RNA from bacterial cultures was extracted by means of the phenol/LiCl extraction method, essentially as described by Eggermont and associates (1996). RNA concentrations were determined fluorimetrically after staining with SYBR Green II in accordance with the manufacturer's protocols (Molecular Probes, Eugene, OR, U.S.A.). A total of $10 \mu \mathrm{g}$ of each RNA sample was separated on a formaldehyde-agarose gel, was transferred to a positively charged nylon membrane, and was hybridized as described previously (Eggermont et al. 1996). To verify equal loading and transfer of RNA, the loading buffer was supplemented with $50 \mu \mathrm{g}$ of ethidium bromide per milliliter, allowing visualization of RNA in the gel and on the blot when illuminated with UV light (Eggermont et al. 1996). To prepare the iaaC riboprobe, an internal $0.5-\mathrm{kb}$ NcoI fragment (Fig. 1) was, after blunting, first cloned into pUC18 and, subsequently as an EcoRI-BamHI fragment, into pBlueScriptIISK + . The digoxigenin (DIG)-labeled antisense transcript was then prepared by in vitro run-off transcription with the DIG RNA labeling kit (SP6/T7) from Roche (Mumbai, Basel, Switzerland), according to the manufacturer's instructtions.

To determine the transcription initiation site of the A. brasilense ipdC gene, primer extension reactions were performed on total RNA isolated from stationary phase A. brasilense Sp245 (pFAJ64) cultures, using the fluoresceine-labeled primers complementary to the $5^{\prime}$ end of the ipdC coding region (DPipdc03AS, 5'-CTCCGCCACCTTGAAGAAGGG-3') or complementary to the $5^{\prime}$ end of the gusA coding region (OWB609, 5'-ACGGGTTGGGGTTTCTACAGGA-3'). The following protocol was used. A mixture of 10 pmol DIG-labeled primer and 50 to $100 \mu \mathrm{g}$ RNA, adjusted to $0.3 \mathrm{M} \mathrm{NaOAc}$ was precipitated with 2.5 vol of EtOH. The pellet was dissolved in $30 \mu \mathrm{l}$ hybridization buffer (containing $80 \%$ formamide, $40 \mathrm{mM}$ piperazine$N, N^{\prime}$-bis(2-ethanesulfonic acid) [PIPES], pH 6.4, $400 \mathrm{mM} \mathrm{NaCl}$, and $1 \mathrm{mM}$ EDTA, $\mathrm{pH} \mathrm{8}$ ) and was denatured for $10 \mathrm{~min}$ at $85^{\circ} \mathrm{C}$. The primer was hybridized to the template for $12 \mathrm{~h}$ at $30^{\circ} \mathrm{C}$, af ter which $170 \mu \mathrm{l}$ of $0.3 \mathrm{M} \mathrm{NaOAc}$ was added and the RNA was precipitated with $2.5 \mathrm{vol}$ of EtOH. For reverse transcription on the precipitated RNA, a reaction mixture containing dNTPs (1 $\mathrm{mM})$, RNAse inhibitor $(0.1 \mathrm{U} / \mu \mathrm{l})$, and AMV reverse transcriptase $(2 \mathrm{U} / \mu \mathrm{l})$ was incubated for $90 \mathrm{~min}$ at $42^{\circ} \mathrm{C}$. Precipitated primer extension products were run on a polyacrylamide gel together with a sequencing reaction carried out with the same primer on pFAJ64a using the AutoRead sequencing kit (Amersham Biosciences).

\section{Construction of an iaaC mutant.}

The pUC19 derivative pUC19-6.5A, containing a $6.5-\mathrm{kb}$ EcoRI fragment and carrying $i p d C$ and $i a a C$, was digested with $B g l \mathrm{II}$ and BamHI, yielding a 4.3-kb BglII-BamHI fragment. The 4.3-kb $B g l$ II-BamHI fragment, carrying the entire iaaC, was subcloned into pSUP202, resulting in pCMPG9250. Site-directed Tn5 mutagenesis on pCMPG9250 using E. coli S17-1::Tn5 yielded pCMPG9250-Tn5a, carrying a Tn5 insertion in iaaC (approximately $300 \mathrm{bp}$ downstream from the putative start codon). pCMPG9250-Tn5a was introduced in $A$. brasilense by triparental mating with HB101(pRK2073) as a helper. Transconjugants were selected on MMAB containing kanamycin. Double recombinants were screened for sensitivity to tetracycline and were verified by Southern hybridization. One of the recombinants showing a correct genetic configuration was named FAJ0010.

\section{Construction of progressive unidirectional deletions in the ipdC upstream region.}

Unidirectional deletions in the region upstream of the ipdC gene were constructed starting from the BamHI site (300 bp upstream of the ipdC start codon) by means of the Erase-aBase system kit (Promega Corp., Leiden, The Netherlands), employing the ipdC-gusA fusion plasmid pFAJ64a as the template. For this, pFAJ64a was digested with BamHI and PstI and then treated with Exonuclease III, S1 nuclease, and Klenow polymerase exactly as described by the manufacturer. In this way, the ipdC promoter region was successively deleted, starting from the unique BamHI site. Colonies containing pFAJ64a derivatives with a deleted ipdC promoter region were selected on LB agar containing ampicillin. A total of 13 derivatives with progressive deletions in the ipdC promoter region (named pFAJ64a.1, pFAJ64a.3 to pFAJ64a.8, pFAJ64a.11, pFAJ64a.12, pFAJ64a.14, pFAJ64a.16, and pFAJ64a.22) were retained, and the exact position of the 5' deletions was determined by DNA sequence analysis. After digestion with EcoRI and HindIII, the deleted promoter regions were subcloned into pLAFR3, yielding pFAJ64.1, pFAJ64.3 to pFAJ64.8, pFAJ64.11, pFAJ64.12, pFAJ64.14, pFAJ64.16, and pFAJ64.22, and then were transferred to $A$. brasilense $\mathrm{Sp} 245$ for expression analysis.

\section{Site-directed mutagenesis of the ipdC upstream region.}

Site-directed mutagenesis of the ipdC promoter region was performed using the QuickChange site-directed mutagenesis kit (Stratagene, La Jolla, CA, U.S.A.) according to the manufacturer's instructions, employing the ipdC-gusA fusion plasmid pFAJ64a as a template. Complementary mutagenesis oligonucleotide pairs incorporating multiple base substitutions and introducing a unique $K p n I$ or $S a c I$ restriction site are listed in Table 1. The temperature cycles used to generate the mutated plasmids were as follows: 1 cycle of $95^{\circ} \mathrm{C}$ for $30 \mathrm{~s}$, then 18 cycles of $95^{\circ} \mathrm{C}$ for $30 \mathrm{~s}, 55^{\circ} \mathrm{C}$ for $1 \mathrm{~min}$, and $68^{\circ} \mathrm{C}$ for $11 \mathrm{~min}$. Correct incorporation of each mutation was first verified by $S a c \mathrm{I}$ or $K p n \mathrm{I}$ restriction analysis and then confirmed by DNA sequencing. The mutated ipdC promotergusA fusions were finally subcloned into pLAFR3 as an EcoRI-HindIII fragment and were transferred by mating to $A$. brasilense Sp245 and FAJ0009 for expression analysis.

\section{ACKNOWLEDGMENTS}

This work was supported by a grant (Onderzoeksproject G.0085.03 to J. Vanderleyden) from the Fund for Scientific Research (F.W.O.Vlaanderen). O. Ona acknowledges the Research Council K.U.Leuven for granting a predoctoral fellowship. 


\section{LITERATURE CITED}

Altschul, S. F., Gish, W., Miller, W., Myers, E. W., and Lipman, D. J. 1990. Basic local alignment search tool. J. Mol. Biol. 215:403-410.

Baldani, V. L. D., Alvarez, M. A. D., Baldani, J. I., and Döbereiner, J. 1986. Establishment of inoculated Azospirillum spp. in the rhizosphere and in roots of field-grown wheat and sorghum. Plant Soil 90:35-46.

Bandyopadhyay, S., and Cookson, M. R. 2004. Evolutionary and functional relationships within the DJ1 superfamily. BMC Evol. Biol. 4:6. Online publication.

Bashan, Y. 1990. Short exposure to Azospirillum brasilense Cd inoculation enhanced proton efflux in intact wheat roots. Can. J. Microbiol. 36:419425.

Becker, G., Klauck, E., and Hengge-Aronis, R. 1999. Regulation of RpoS proteolysis in Escherichia coli: The response regulator RssB is a recognition factor that interacts with the turnover element in RpoS. Proc. Natl. Acad. Sci. U.S.A. 96:6439-6444.

Bialek, K., and Cohen, J. D. 1986. Isolation and partial characterization of the major amide-linked conjugate of indole-3-acetic acid from Phaseolus vulgaris L. Plant Physiol. 80:99-104.

Bozouklian, H., and Elmerich, C. 1986. Nucleotide sequence of the Azospirillum brasilense $\mathrm{Sp} 7$ glutamine synthetase structural gene. Biochimie 68:1181-1187.

Brandl, M. T., and Lindow, S. E. 1996. Cloning and characterization of a locus encoding an indolepyruvate decarboxylase involved in indole-3acetic acid synthesis in Erwinia herbicola. Appl. Environ. Microbiol. 62:4121-4128.

Brandl, M. T., and Lindow, S. E. 1997. Environmental signals modulate the expression of an indole-3-acetic acid biosynthetic gene in Erwinia herbicola. Mol. Plant-Microbe Interact. 10:499-505.

Brandl, M. T., Quinones, B., and Lindow, S. E. 2001. Heterogeneous transcription of an indole acetic acid biosynthetic gene in Erwinia herbicola on plant surfaces. Proc. Natl. Acad. Sci. U.S.A. 98:3454-3459.

Capela, D., Barloy-Hubler, F., Gouzy, J., Bothe, G., Ampe, F., Batut, J., Boistard, P., Becker, A., Boutry, M., Cadieu, E., Dreano, S., Gloux, S., Godrie, T., Goffeau, A., Kahn, D., Kiss, E., Lelaure, V., Masuy, D., Pohl, T., Portetelle, D., Puhler, A., Purnelle, B., Ramsperger, U. Renard, C., Thebault, P., Vandenbol, M., Weidner, S., and Galibert, F. 2001. Analysis of the chromosome sequence of the legume symbiont Sinorhizobium meliloti strain 1021. Proc. Natl. Acad. Sci. U.S.A. 98:9877-9882.

Carrillo, A. E., Li, C. Y. and Bashan, Y. 2002. Increased acidification in the rhizosphere of cactus seedlings induced by Azospirillum brasilense. Naturwissenschaften 89:428-432.

Comai, L., and Kosuge, T. 1982. Cloning characterization of iaaM, a virulence determinant of Pseudomonas savastanoi. J. Bacteriol. 149:40-46.

Costacurta, A., and Vanderleyden, J. 1995. Synthesis of phytohormones by plant-associated bacteria. Crit. Rev. Microbiol. 21:1-18.

Costacurta, A., Keijers, V., and Vanderleyden, J. 1994. Molecular cloning and sequence analysis of an Azospirillum brasilense indole-3-pyruvate decarboxylase gene. Mol. Gen. Genet. 243:463-472.

de Nobel, H., Lawrie, L., Brul, S., Klis, F., Davis, M., Alloush, H., and Coote, P. 2001. Parallel and comparative analysis of the proteome and transcriptome of sorbic acid-stressed Saccharomyces cerevisiae. Yeast 18:1413-1428.

Dharmasiri, S., and Estelle, M. 2002. The role of regulated protein degradation in auxin response. Plant Mol. Biol. 49:401-409.

Dobbelaere, S., Croonenborghs, A., Thys, A., Vande Broek, A., and Vanderleyden, J. 1999. Phytostimulatory effect of Azospirillum brasilense wild type and mutant strains altered in IAA production on wheat. Plant Soil 212:155-164.

Eckardt, N. A. 2001. New insights into auxin biosynthesis. Plant Cell $13: 1-3$.

Eggermont, K., Goderis, I. J., and Broekaert, W. F. 1996. High-throughput RNA extraction from plant samples based on homogenisation by reciprocal shaking in the presence of a mixture of sand and glass beads. Plant Mol. Biol. Rep. 14:273-279.

Ferreira, A., O'Byrne, C. P., and Boor, K. J. 2001. Role of $\sigma^{\mathrm{B}}$ in heat, ethanol, acid, and oxidative stress resistance and during carbon starvation in Listeria monocytogenes. Appl. Environ. Microbiol. 67:4454-4457.

Figurski, D. H., and Helinski, D. R. 1979. Replication of an origin-containing derivative of plasmid RK2, dependent on a plasmid function provided in trans. Proc. Natl. Acad. Sci. U.S.A. 76:1648-1652.

Gaidenko, T. A., and Price, C. W. 1998. General stress transcription factor $\sigma^{\mathrm{B}}$ and sporulation transcription factor $\sigma^{\mathrm{H}}$ each contribute to survival of Bacillus subtilis under extreme growth conditions. J. Bacteriol. 180:3730-3733

Gralla, J. D., and Collado-Vides, J. 1996. Organization and function of transcription regulatory elements. Pages 1232-1245 in: Escherichia coli and Salmonella: Cellular and Molecular Biology, F. C. Neidhardt, ed. American Society for Microbiology Press, Washington, D.C.

Hagen, G., and Guilfoyle, T. J. 2002. Auxin-responsive gene expression: Genes, promoters and regulatory factors. Plant Mol. Biol. 49:373-385.

Halio, S. B., Blumentals, I. I., Short, S. A., Merrill, B. M., and Kelly, R. M. 1996. Sequence, expression in Escherichia coli, and analysis of the gene encoding a novel intracellular protease (PfpI) from the hyperthermophilic archaeon Pyrococcus furiosus. J. Bacteriol. 178:2605-2612.

Hellmann, H., and Estelle, M. 2002. Plant development: Regulation by protein degradation. Science 297:793-797.

Hengge-Aronis, R. 2002. Recent insights into the general stress response regulatory network in Escherichia coli. J. Mol. Microbiol. Biotechnol. 4:341-346.

Hod, Y., Pentyala, S. N., Whyard, T. C., and El Maghrabi, M. R. 1999. Identification and characterization of a novel protein that regulates RNA-protein interaction. J. Cell. Biochem. 72:435-444.

Jefferson, R. A. 1987. Assaying chimeric genes in plants: The GUS gene fusion system. Plant Mol. Biol. Rep. 5:387-405.

Jenal, U., and Hengge-Aronis, R. 2003. Regulation by proteolysis in bacterial cells. Curr. Opin. Microbiol. 6:163-172.

Kapulnik, Y., Okon, Y., and Henis, Y. 1985. Changes in root morphology of wheat caused by Azospirillum inoculation. Can. J. Microbiol. 31:881-887.

Kepinski, S., and Leyser, O. 2002. Ubiquitination and auxin signaling: A degrading story. Plant Cell 14:S81-S95.

Klauck, E., Lingnau, M., and Hengge-Aronis, R. 2001. Role of the response regulator RssB in $\sigma^{\mathrm{S}}$ recognition and initiation of $\sigma^{\mathrm{S}}$ proteolysis in Escherichia coli. Mol. Microbiol. 40:1381-1390.

Koga, J., Adachi, T., and Hidaka, H. 1991. Molecular cloning of the gene for indolepyruvate decarboxylase from Enterobacter cloacae. Mol. Gen. Genet. 226:10-16.

Lambrecht, M., Vande Broek, A., Dosselaere, F., and Vanderleyden, J. 1999. The ipdC promoter auxin-responsive element of Azospirillum brasilense, a prokaryotic ancestral form of the plant AuxRE? Mol. Microbiol. 32:889-891.

Lee, I. S., Lin, J. S., Hall, H. K., Bearson, B., and Foster, J. W. 1995. The stationary-phase sigma factor $\sigma^{\mathrm{S}}(\mathrm{RpoS})$ is required for a sustained acid tolerance response in virulent Salmonella typhimurium. Mol. Microbiol. 17:155-167.

Lee, S. J., Kim, S. J., Kim, I. K., Ko, J., Jeong, C. S., Kim, G. H., Park, C., Kang, S. O., Suh, P. G., Lee, H. S., and Cha, S. S. 2003. Crystal structures of human DJ-1 and Escherichia coli Hsp31, which share an evolutionarily conserved domain. J. Biol. Chem. 278:44552-44559.

Lewis, M., Chang, G., Horton, N. C., Kercher, M. A., Pace, H. C., Schumacher, M. A., Brennan, R. G., and Lu, P. Z. 1996. Crystal structure of the lactose operon repressor and its complexes with DNA and inducer. Science 271:1247-1254.

Ljung, K., Hull, A. K., Kowalczyk, M., Marchant, A., Celenza, J., Cohen, J. D., and Sandberg, G. 2002. Biosynthesis, conjugation, catabolism and homeostasis of indole-3-acetic acid in Arabidopsis thaliana. Plant Mol. Biol. 50:309-332.

Miller, J.H. 1972. Experiments in Molecular Genetics. Cold Spring Harbor Laboratory Press, Cold Spring Harbor, NY, U.S.A.

Mizote, T., Tsuda, M., Nakazawa, T., and Nakayama, H. 1996. The thiJ locus and its relation to phosphorylation of hydroxymethylpyrimidine in Escherichia coli. Microbiology 142:2969-2974.

Moreno, M., Audia, J. P., Bearson, S. M. D., Webb, C., and Foster, J. W. 2000. Regulation of $\sigma^{\mathrm{S}}$ degradation in Salmonella enterica var. typhimurium: In vivo interactions between $\sigma^{\mathrm{S}}$, the response regulator MviA(RssB) and ClpX. J. Mol. Microbiol. Biotechnol. 2:245-254.

Nicholas, K. B., Nicholas, H. B. J., and Deerfield, D. W. 1997. GeneDoc: Analysis and visualization of genetic variation. EMBNet Newsletter $4: 1-4$

Patten, C. L., and Glick, B. R. 1996. Bacterial biosynthesis of indole-3acetic acid. Can. J. Microbiol. 42:207-220.

Patten, C. L., and Glick, B. R. 2002a. Regulation of indole acetic acid production in Pseudomonas putida GR12-2 by tryptophan and the stationary-phase sigma factor RpoS. Can. J. Microbiol. 48:635-642.

Patten, C. L., and Glick, B. R. 2002b. Role of Pseudomonas putida indole acetic acid in development of the host plant root system. Appl. Environ. Microbiol. 68:3795-3801.

Prinsen, E., Costacurta, A., Michiels, K., Vanderleyden, J., and Vanonckelen, H. 1993. Azospirillum brasilense indole-3-acetic acid biosynthesis: Evidence for a non-tryptophan dependent pathway. Mol. Plant-Microbe Interact. 6:609-615.

Prinsen, E., Van Laer, S., Oden, S., and Van Onckelen, H. 2000. Auxin analysis. Meth. Mol. Biol. 141:49-65.

Prusty, R., Grisafi, P., and Fink, G. R. 2004. The plant hormone indole acetic acid induces invasive growth in Saccharomyces cerevisiae. Proc. Natl. Acad. Sci. U.S.A. 101:4153-4157. 
Sambrook, J., Fritsch, E. F., and Maniatis, T. 1989. Molecular Cloning: A Laboratory Manual. 2nd ed. Cold Spring Harbor Laboratory Press, Cold Spring Harbor, NY, U.S. A.

Sastry, M. S. R., Korotkov, K., Brodsky, Y., and Baneyx, F. 2002. Hsp31, the Escherichia coli yedU gene product, is a molecular chaperone whose activity is inhibited by ATP at high temperatures. J. Biol. Chem. 277:46026-46034.

Schreiber, V., Steegborn, C., Clausen, T., Boos, W., and Richet, E. 2000. A new mechanism for the control of a prokaryotic transcriptional regulator: Antagonistic binding of positive and negative effectors. Mol. Microbiol. 35:765-776.

Schütz, A., Sandalova, T., Ricagno, S., Hübner, G., König, S., and Schneider, G. 2003. Crystal structure of thiamindiphosphate-dependent indolepyruvate decarboxylase from Enterobacter cloacae, an enzyme involved in the biosynthesis of the plant hormone indole-3-acetic acid. Eur. J. Biochem. 270:2312-2321.

Sergeeva, E., Liaimer, A., and Bergman, B. 2002. Evidence for production of the phytohormone indole-3-acetic acid by cyanobacteria. Planta 215:229-238.

Simon, R., Priefer, U., and Pühler, A. 1983. A broad host range mobilization system for in vivo genetic engineering: Transposon mutagenesis in gram negative bacteria. Biotechnol. 1:784-791.

Small, P., Blankenhorn, D., Welty, D., Zinser, E., and Slonczewski, J. L. 1994. Acid and base resistance in Escherichia coli and Shigella flexneri: Role of $r p o S$ and growth pH. J. Bacteriol. 176:1729-1737.

Soto-Urzua, L., Xochinua-Corona, Y. G., Flores-Encarnacion, M., and Baca, B. E. 1996. Purification and properties of aromatic amino acid aminotransferases from Azospirillum brasilense UAP 14 strain. Can. J. Microbiol. 42:294-298.

Staskawicz, B., Dahlbeck, D., Keen, N., and Napoli, C. 1987. Molecular characterization of cloned avirulence genes from race 0 and race 1 of Pseudomonas syringae pv. glycinea. J. Bacteriol. 169:5789-5794.

Tam, Y. Y., and Normanly, J. 1998. Determination of indole-3-pyruvic acid levels in Arabidopsis thaliana by gas chromatography-selected ion monitoring-mass spectrometry. J. Chromatogr. A 800:101-108.

Thomashow, L. S., Reeves, S., and Thomashow, M. F. 1984. Crown gall oncogenesis: Evidence that a T-DNA gene from the Agrobacterium Ti plasmid pTiA6 encodes an enzyme that catalyzes synthesis of indole acetic acid. Proc. Natl. Acad. Sci. U.S.A. 81:5071-5075.

Thompson, J. D., Higgins, D. G., and Gibson, T. J. 1994. CLUSTAL W: Improving the sensitivity of progressive multiple sequence alignment through sequence weighting, position-specific gap penalties and weight matrix choice. Nucleic Acids Res. 22:4673-4680.
Trotter, E. W., Kao, C. M. F., Berenfeld, L., Botstein, D., Petsko, G. A. and Gray, J. V. 2002. Misfolded proteins are competent to mediate a subset of the responses to heat shock in Saccharomyces cerevisiae. J. Biol. Chem. 277:44817-44825.

Ulmasov, T., Liu, Z. B., Hagen, G., and Guilfoyle, T. J. 1995. Composite structure of auxin response elements. Plant Cell 7:1611-1623.

Vande Broek, A., Keijers, V., and Vanderleyden, J. 1996. Effect of oxygen on the free-living nitrogen fixation activity and expression of the Azospirillum brasilense NifH gene in various plant-associated diazotrophs. Symbiosis 21:25-40.

Vande Broek, A., Lambrecht, M., Eggermont, K., and Vanderleyden, J. 1999. Auxins upregulate expression of the indole-3-pyruvate decarboxylase gene in Azospirillum brasilense. J. Bacteriol. 181:1338-1342.

Vanstockem, M., Michiels, K., Vanderleyden, J., and Van Gool, A. P. 1987. Transposon mutagenesis of Azospirillum brasilense and Azospirillum lipoferum: Physical analysis of Tn5 and Tn5-mob insertion mutants. Appl. Environ. Microbiol. 53:410-415.

Walz, A., Park, S., Slovin, J. P., Ludwig-Muller, J., Momonoki, Y. S., and Cohen, J. D. 2002. A gene encoding a protein modified by the phytohormone indole acetic acid. Proc. Natl. Acad. Sci. U.S.A. 99:1718-1723.

Wang, F. L., and Lee, S. Y. 1997. Production of poly(3-hydroxybutyrate) by fed-batch culture of filamentation-suppressed recombinant Escherichia coli. Appl. Environ. Microbiol. 63:4765-4769.

Wiedmann, M., Arvik, T. J., Hurley, R. J., and Boor, K. J. 1998. General stress transcription factor $\sigma^{\mathrm{B}}$ and its role in acid tolerance and virulence of Listeria monocytogenes. J. Bacteriol. 180:3650-3656.

Wilson, M. A., St. Amour, C. V., Collins, J. L., Ringe, D., and Petsko, G. A. 2004. The 1.8- $\AA$ resolution crystal structure of YDR533Cp from Saccharomyces cerevisiae: A member of the DJ-1/ThiJ/PfpI superfamily. Proc. Natl. Acad. Sci. U.S.A. 101:1531-1536.

Yagi, K., Chujo, T., Nojiri, H., Omori, T., Nishiyama, M., and Yamane, H. 2001. Evidence for the presence of DNA-binding proteins involved in regulation of the gene expression of indole-3-pyruvic acid decarboxylase, a key enzyme in indole-3-acetic acid biosynthesis in Azospirillum lipoferum FS. Biosci. Biotechnol. Biochem. 65:1265-1269.

Yanisch-Perron, C., Vieira, J., and Messing, J. 1985. Improved M13 phage cloning vectors and host strains: Nucleotide sequences of the M13mp18 and pUC19 vectors. Gene 33:103-119.

\section{AUTHOR-RECOMMENDED INTERNET RESOURCE}

Pfam 7.3 database: pfam.wustl.edu/hmmsearch.shtml 